\title{
Vine nitrogen status and volatile thiols and their precursors from plot to transcriptome level
}

Pierre Helwi 1,2,3, Sabine Guillaumie ${ }^{1,3}$, Cécile Thibon ${ }^{4,5}$, Céline Keime ${ }^{6}$, Aude Habran ${ }^{1,3}$, Ghislaine Hilbert ${ }^{1,3}$, Eric Gomes ${ }^{1,3}$, Philippe Darriet ${ }^{4,5}$, Serge Delrot ${ }^{1,3}$ and Cornelis van Leeuwen ${ }^{2^{*}}$

\begin{abstract}
Background: Volatile thiols largely contribute to the organoleptic characteristics and typicity of Sauvignon blanc wines. Among this family of odorous compounds, 3-sulfanylhexan-1-ol (3SH) and 4-methyl-4-sulfanylpentan-2-one (4MSP) have a major impact on wine flavor. These thiols are formed during alcoholic fermentation by the yeast from odorless, non-volatile precursors found in the berries and the must. The present study investigates the effects of vine nitrogen $(\mathrm{N})$ status on $3 \mathrm{SH}$ and 4MSP content in Sauvignon blanc wine and on the glutathionylated and cysteinylated precursors of $3 \mathrm{SH}$ (Glut-3SH and $\mathrm{Cys}-3 \mathrm{SH}$ ) in the berries and the must. This is paralleled by a RNA-seq analysis of gene expression in the berries. The impact of $\mathrm{N}$ supply on the expression of the glutathione-S-transferase 3 and 4 (VviGST3 and VviGST4) and the $\gamma$-glutamyltranspeptidase (VviGGT), considered as key genes in their biosynthesis, was also evaluated.
\end{abstract}

Results: N supply (N100 treatment) increased the 3SH content in wine while no effect was noticed on 4MSP level. Furthermore, N supply increased Glut-3SH levels in grape berries at late berry ripening stages, and this effect was highly significant in must at harvest. No significant effect of $\mathrm{N}$ addition was noticed on Cys-3SH concentration. The transcript abundance of the glutathione-S-transferases VviGST3 and VViGST4 and the $\gamma$-glutamyltranspeptidase (VviGGT), were similar between the control and the N100 treatment. New candidate genes which might be implicated in the biosynthetic pathway of $3 \mathrm{SH}$ precursors were identified by whole transcriptome shotgun sequencing (RNA-seq).

Conclusions: High vine N status has a positive effect on 3SH content in wine through an increase of Glut-3SH levels in grape berries and must. Candidate GSTs and glutathione-S-conjugates type transporters involved in this stimulation were identified by RNA-seq analysis.

Keywords: Vitis vinifera, Nitrogen, Volatile thiols, 3-sulfanylhexan-1-ol, 4-methyl-4-sulfanylpentan-2-one, Glutathionylated precursors, Cysteinylated precursors, GST, GGT

\section{Background}

Aroma compounds contribute to a large extent to the organoleptic characteristics and typicity of wine. Slight differences in the concentrations of these volatile molecules create diverse wine aroma profiles $[1,2]$. Wine aromas can be classified into three main groups according to their origin: "varietal" aromas specific for grape varieties, "winemaking" aromas produced during the

\footnotetext{
* Correspondence: vanleeuwen@agro-bordeaux.fr

${ }^{2}$ Bordeaux Sciences Agro, Institut des Sciences de la Vigne et du Vin (ISW), Ecophysiologie et Génomique Fonctionnelle de la Vigne (EGFV), UMR 1287, 33140 Villenave d'Ornon, France

Full list of author information is available at the end of the article
}

fermentations and "mature" aromas developed during aging [3].

Varietal aroma compounds play a major role in the oenological potential of the wine. In addition to grape variety, their concentrations also depend on soil and climate [4]. Some varietal aroma compounds like pyrazines $[5,6]$, terpenols [7] and rotundone [8] exist as free compounds that are directly perceivable by the olfactory receptors. Others are present as non-volatile and odorless precursors in the grape berry and their cleavage into fragrant compounds occurs during winemaking and/or aging. Among the latter, major contributors to wine 
aromas are volatile thiols, monoterpènes, C13norisoprenoids, dimethylsulfide, volatile phenols, C6 compounds and furaneol $[9,10]$.

Volatile thiols represent a large family of molecules that contribute positively or negatively to the aromatic potential of the wines [11]. Many odorous thiols were identified in the early 1990s in Sauvignon blanc wines [12, 13]. Subsequently, these thiols were identified in a large panel of cultivars like Semillon, Riesling, Pinot gris and Colombard [14]. Among them, 4-methyl-4-sulfanylpentan-2-one (4MSP) and 3-sulfanylhexan-1-ol (3SH) identified by Darriet et al. (1995) and Tominaga et al. (1998) respectively, play an important role in the aroma of these varieties $[12,13]$. In Sauvignon blanc wines, the 4MSP has a strong box-tree odor and the $3 \mathrm{SH}$ has a smell of grapefruit or passion fruit. The latter can be transformed during the alcoholic fermentation into its acetate reminiscent to boxwood, grapefruit zest and passion fruit [14]. The 4MSP and $3 \mathrm{SH}$ are not present in berries and musts, but they are generated during the alcoholic fermentation from non-volatile and odorless berry precursors. The known forms of these precursors in berries are $S$-conjugates to glutathione or to cysteine: $S$-4-(4-methylpentan-2-one)-Lglutathione (Glut-4MSP) and S-4-(4-methylpentan-2one)-L-cysteine (Cys-4MSP) for the 4MSP respectively and $S$-3-(hexan-1-ol)-glutathione (Glut-3SH) and $S$-3(hexan-1-ol)-cysteine (Cys-3SH) for the $3 \mathrm{SH}$ respectively [15-18]. The release of the volatile thiol from their precursors occurs during the fermentation by a $\beta$-lyase-like activity of Saccharomyces cerevisiae that induces the cleavage of carbon-sulfur bonds [15-17, 19, 20]. The biosynthetic pathways of these precursors in grape are still far from being fully understood, although some results have been published with regards to $3 \mathrm{SH}$ precursors. Peyrot des Gachons [16] assumed that the cysteinylated precursor of 3SH derives from the catabolism of the glutathionylated precursor. However this reaction requires the presence of two enzymes: a $\gamma$-glutamyltranspeptidase (VviGGT) which catalyzes the elimination of the glutamic acid, and a carboxypeptidase responsible for removing the glycine to produce the Cys-3SH. Recent studies also showed the formation of Cys-3SH in cell cultures of Vitis vinifera from Glut-3SH [21, 22]. The latter derives from an intermediate form, Glut-3SH-al, which is formed by the combination of the glutathione (GSH) with the trans2-hexenal [23, 24]. This step could happen spontaneously and/or by the action of a glutathione-S-transferase enzyme (VviGST, Fig. 1) [23, 25, 26]. Kobayashi et al. described three genes in Sauvignon blanc berries putatively implicated in the synthesis of 3SH precursors: VviGST3, VviGST4 and VviGGT [27].

In Sauvignon blanc berries and during ripening, the accumulation and the concentration of 4MSP and $3 \mathrm{SH}$ precursors largely depend on environmental factors like climate and soil composition [4, 28]. Among the nutrients vines absorbed from the soil, nitrogen $(\mathrm{N})$ greatly influences the content of 4MSP and $3 \mathrm{SH}$ in wine and its precursors in grapes $[4,28,29]$. $\mathrm{N}$ supply enhances their synthesis and their accumulation in Sauvignon blanc grape berries, musts and wines [28, 29]. However, an increase of precursors levels in grapes and musts is not always correlated with an increase of $3 \mathrm{SH}$ content in wine due to nitrogen catabolite repression or other factors (phenols content, sugar level, pH...) during fermentation [30].

In the present study, the effect of vine $\mathrm{N}$ status on 4MSP and 3SH content in wines was confirmed. The impact of $\mathrm{N}$ status on the accumulation of Glut-3SH and $\mathrm{Cys}-3 \mathrm{SH}$ in grape berries during ripening and in musts was explored. Moreover VviGST3, VviGST4 and $V v i G G T$ expression profiling was evaluated to determine their responses to $\mathrm{N}$ addition and their implication in $3 \mathrm{SH}$ synthesis. Furthermore, an identification of potential candidate genes that might be involved in the biosynthetic pathway of $3 \mathrm{SH}$ was performed by whole transcriptome shotgun sequencing (RNA-seq).

The objective of this study was to gain a better understanding on $3 \mathrm{SH}$ synthesis through monitoring of $3 \mathrm{SH}$ precursors genesis in grape berries and musts, $3 \mathrm{SH}$ liberation in wine and expression profiling of candidate genes during key stages in grape ripening under different levels of vine $\mathrm{N}$ status.

\section{Methods}

\section{Location, vine material and experimental set up}

Experiments were set up in commercial vineyards located in Pessac-Léognan area, Bordeaux, France (Château Couhins) and Sancerre area, France (Domaine Fontaine-Audon). Planting density was 6667 vines ha ${ }^{-1}$ in Château Couhins and 7000 vines $\mathrm{ha}^{-1}$ at domaine Fontaine-Audon. The study was performed on Sauvignon blanc vines (Vitis vinifera L.) in 2013 and 2014 (clone 316 grafted on Fercal in 2013 and clone 108 grafted on 161-49 C in 2014 in Bordeaux; clone 905 grafted on 3309 C in 2013 and 2014 in Sancerre). Experimental plots were selected for their low $\mathrm{N}$ status in previous years (Yeast Available Nitrogen $(Y A N)<$ $100 \mathrm{mg} \mathrm{L}^{-1}$ ). On each plot, two treatments were compared: control without fertilization and soil N100: $100 \mathrm{~kg}$ per hectare of nitrogen applied to the soil in two applications (bud break and flowering). Each treatment was repeated by means of four randomized replicates of ten vines each. Ammonium nitrate $\left(\mathrm{NH}_{4} \mathrm{NO}_{3}\right)$ containing $33 \%$ of $\mathrm{N}$ was used as fertilizer. Irrigation was managed during the whole season to avoid possible water deficit. In both vineyards, vines were double Guyot trained and all viticultural practices were identical for both modalities. No leaf removal or cluster and shoot 


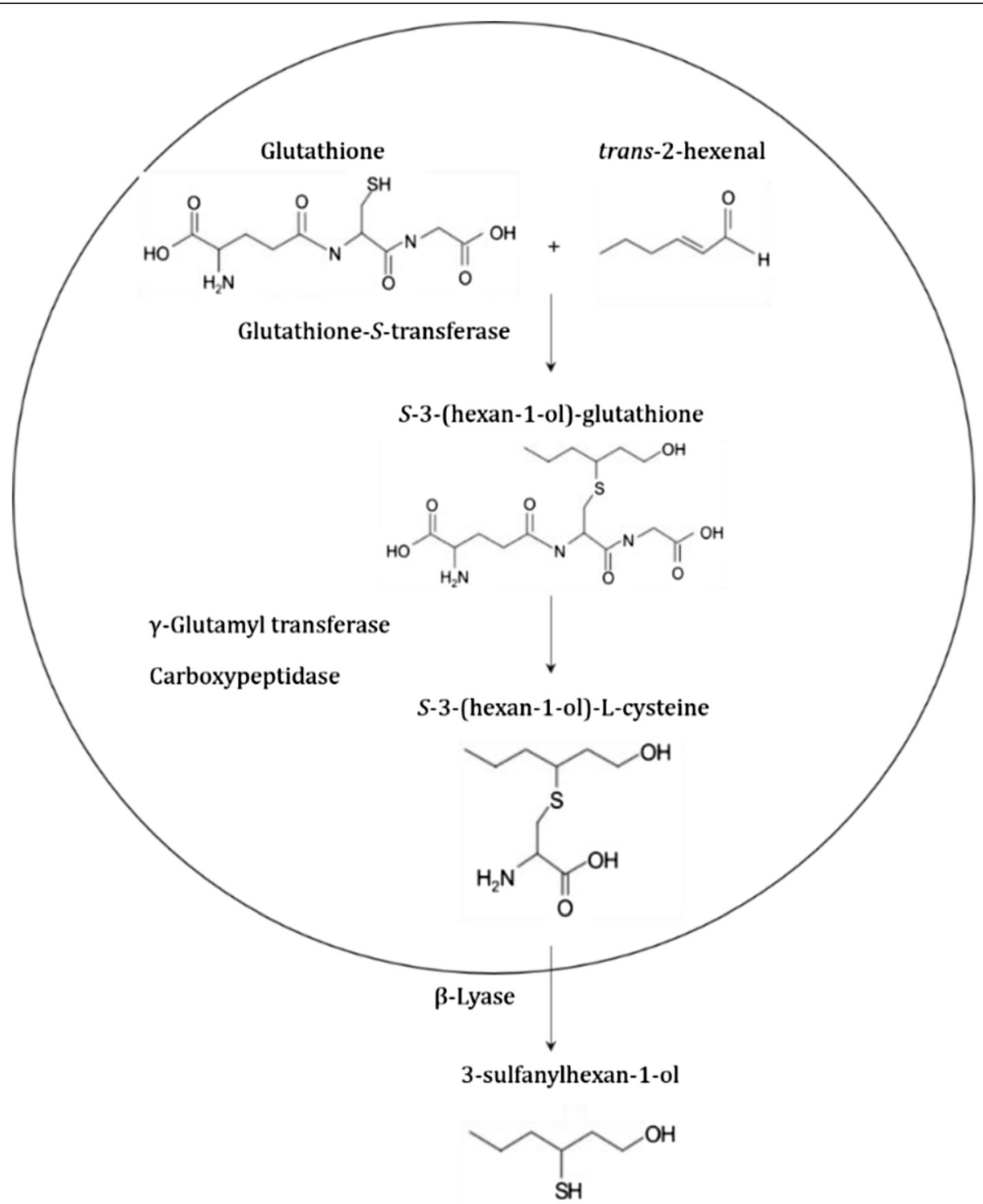

Fig. 1 Hypothetical pathway of the glutathionylated precursor (Glut-3SH) and cysteinylated precursor (Cys-3SH) of 3SH in grape berries as described by Kobayashi et al. and Thibon et al. [21, 22]. In the berry, illustrated as a circle, Glut-3SH derives from Glut-3SH-al, which is formed by the combination of the glutathione (GSH) with the trans-2-hexenal. In the must, the production of 3-sulfanylhexan-1-ol (3SH) occurs during the alcoholic fermentation by the yeast

thinning were carried out. Approximately 100 fresh berries were randomly collected per treatment from each block at three different developmental stages: midveraison (v), mid-ripening (28 days after mid-veraison; $\mathrm{v}+28$ ) and ripeness (35 days after mid-veraison; $\mathrm{v}+35)$. Mid-veraison was determined as the time when $50 \%$ of the berries were soft. Berries were cut at the pedicel without wounding berry skin and were frozen immediately in liquid nitrogen, ground and stored at $-80^{\circ} \mathrm{C}$.

\section{Vine water status}

Vine water status was monitored during the season by measuring the leaf water potential with a pressure chamber [31]. Measurements were carried out at midday on three primary leaves per block covered with an opaque plastic bag $1 \mathrm{~h}$ prior to measurement [32]. Irrigation was implemented when leaf water potential was close to $-1 \mathrm{MPa}$, in order to avoid vine water deficit stress.

\section{Vine vigor}

Vine vigor was assessed by measuring primary and secondary leaf areas and yield at harvest. To determine leaf areas, a correlation curve was established between the length of primary and secondary shoots and their corresponding leaf area using a LI-3100 LICOR leaf area 
meter (Lincoln, Nebraska, USA). Subsequently, the length of all primary and secondary shoots of two vines per replicate was measured and primary and secondary leaf areas were deduced from the correlation obtained between shoot length and shoot leaf area, according to Mabrouk and Carbonneau [33]. Yield was determined for each elementary plot at harvest by weighing all grape bunches of ten vines per replicate.

\section{Vine and berry nitrogen status}

$\mathrm{N}$-tester measurements (N-tester, Norsk Hydro, 00-12 Oslo, Norway) and Yeast Available Nitrogen (YAN) were used to assess vine $\mathrm{N}$ status [34]. N-tester measures leaf blade color intensity which is in relation with the chlorophyll concentration and the $\mathrm{N}$ status. Measurements were performed on thirty primary leaves in the bunch zone across each block in order to obtain an average value representing vine $\mathrm{N}$ status [34, 35]. YAN was assessed in grape juice obtained by pressing approximately 100 berries collected at harvest stage. The juice was analyzed with a Fourier Transform Infra-Red spectrometer (FTIR, WineScan FOSS ${ }^{\oplus}$ FRANCE, 92000 Nanterre) [36].

\section{Berry and must composition}

Harvest in Bordeaux vineyard occurred on September 23 in 2013 and on September 08 in 2014. In Sancerre, these dates were respectively October 10 in 2013 and September 25 in 2014. One day prior to these dates, approximately 25 berries were collected in liquid nitrogen for primary metabolite analyses and 100 berries were sampled and pressed to obtain grape must. Primary metabolites of berries were extracted from $250 \mathrm{mg}$ of frozen berry material ground to powder, with $80 \%$ ethanol at $80{ }^{\circ} \mathrm{C}$ for $15 \mathrm{~min}$ followed by two extractions with respectively $50 \%$ ethanol and ultrapure water. Glucose and fructose were assessed using an enzymatic method (glucose/fructose kit from BioSenTec, BioSenTec, F-31000 Toulouse, France). Malic acid was measured using a colorimetric method (Bran and Luebbe TRAACS 800 autoanalyzer, 22844 Norderstedt, Germany).

Grape must was obtained by pressing 100 berries. After centrifugation, it was analyzed using a WineScan ${ }^{\text {тм }}$ Auto analyzer (WineScan FOSS ${ }^{\circledR}$, FRANCE, 92000 Nanterre) according to Destrac et al. [36]. Sugar, total acidity, $\mathrm{pH}$ and malic acid contents were measured twice on each sample through two successive determinations.

\section{Microvinification}

Microvinifications were conducted on Sauvignon blanc from each plot in Bordeaux and Sancerre as described [6]. In Bordeaux, one kilogram of grapes were pressed manually and in Sancerre, $20 \mathrm{~kg}$ of grapes were pressed with a small wine press (Socma, 11100 Narbonne, France). In Bordeaux and Sancerre, must was inoculated with X5 yeast strain (ZYMAFLORE X5 - Laffort, final concentration of $20 \mathrm{mg} \mathrm{mL}^{-1}$ ) and fermentations were carried on $100 \mathrm{~mL}$ and $5 \mathrm{~L}$ of must respectively at $20^{\circ} \mathrm{C}$.

\section{Quantification of $4 \mathrm{MSP}$ and $3 \mathrm{SH}$ in wines}

For $50 \mathrm{~mL}$ of centrifuged wine, $2 \mathrm{mM}$ of $p$-hydroxymercuribenzoate diluted in $0.1 \mathrm{M}$ Tris and $50 \mu \mathrm{L}$ of internal standard mix (6-sulfanylhexanol: 6SH, $30 \mu \mathrm{mol} \mathrm{L} \mathrm{L}^{-1}$, and 4methoxy-2-methyl-2-sulfanylbutan: MMSB, $30 \mu \mathrm{mol} \mathrm{L}{ }^{-1}$ ) were added successively. Sample $\mathrm{pH}$ was adjusted to 7.0 (with concentrated $\mathrm{NaOH}$ solution), and then purified on an ion exchange resin (Dowex 1, Sigma; 1x2-100) previously activated for $15 \mathrm{~min}$ with $\mathrm{HCl}(0.1 \mathrm{M})$ and washed with water until its $\mathrm{pH}$ reached a value of 5.0. The resin was washed with an acetate buffer (50 mL, $0.1 \mathrm{M}, \mathrm{pH} 7.0$ ) and subsequently thiols were eluted by a cysteine buffer (50 mL, $10 \mathrm{~g} \mathrm{~L}^{-1}, \mathrm{pH}$ 7). The flow-through was collected, mixed with $500 \mu \mathrm{L}$ of ethyl acetate and volatile thiols were extracted twice with dichloromethane ( $4 \mathrm{~mL}$ than $3 \mathrm{~mL}$ ). The organic phase containing thiols was dried with anhydrous sodium sulfate and then concentrated to obtain a final volume of $50 \mu \mathrm{L}$. Samples were analyzed by gas chromatography coupled to mass spectrometry (GC-MS) as described [37].

\section{Extraction and quantification of $3 \mathrm{SH}$ precursors from berries and grape musts}

The extraction and the quantification of $3 \mathrm{SH}$ precursors in grape berries and musts was performed as described [38]. In brief, the purification was carried on a mix of $1 \mathrm{~mL}$ of grape juice obtained by defrosting of $2 \mathrm{~g}$ of frozen berry powder in the presence of sulfur dioxide (200 $\mathrm{mg} \mathrm{L}^{-1}$ ) or directly from grape must, $1 \mathrm{~mL}$ of water and a final concentration of $50 \mu \mathrm{g} \mathrm{L}^{-1}$ of the internal standard solution containing a deuterated form of the glutathionylated $S$-conjugate of $3 \mathrm{SH}$ ((3-S-hexan-1-ol)glutathione- $\mathrm{d}_{3}$ ) percolated through a SPE columns (LC$18500 \mathrm{mg} 6 \mathrm{~mL}$, Supelco France, Saint Germain-Laye, France). Precursors were eluted with $3 \mathrm{~mL}$ of methanol/ water $(30 / 70 ; \mathrm{v} / \mathrm{v})$ in hemolysis tubes. The flow-through was subsequently evaporated and residues were dissolved in $700 \mu \mathrm{L}$ of aqueous formic acid solution (0.1\%). Quantification was done using an Accela UHPLC (Thermo Fisher Scientific) connected in series to an Exactive (Thermo Fisher Scientific, Bremen, Germany) mass spectrometer equipped with a heated ESI ion source (LC-ESI-MS). The separation was performed on a Synchronis aQ column $(100 \times 2.1 \mathrm{~mm}$ i.d., $1.7 \mu \mathrm{m}$, Synchronis aQ, Thermo Scientific, Bremen, Germany) with a flow rate of $300 \mu \mathrm{L} \mathrm{min}$ m $^{-1}$ of solvent A $(0.1 \%$ aqueous formic acid) and solvent B (0.1\% formic acid in 
acetonitrile). The ion source was operated in the positive ion mode at $3.5 \mathrm{kV}$.

\section{RNA extraction and gene expression analysis}

Total RNAs were isolated according to Reid et al. [39] from $1 \mathrm{~g}$ of grounded frozen berries from Bordeaux in 2013 and 2014. Traces of genomic DNA were removed by a DNAse I treatment according to the manufacturer's instructions (Ambion TURBO DNA-free DNase, Life Technologies). RNAs were quantified using a Nanodrop 2000c spectrophotometer (Thermo Scientific) and checked for integrity on an $1.8 \%$ agarose gel. For cDNA synthesis, $1.5 \mu \mathrm{g}$ of total RNA were reverse transcribed with OligodT primers in an $20 \mu \mathrm{L}$ reaction mixture using SuperScript III reverse transcriptase (Invitrogen) according to the manufacturer's instructions.

Relative transcript quantification of VviGSTs, VviGGT and $V v i N i R$ genes was achieved by quantitative real-time PCR using a CFX96 Real-Time PCR Detection system (Bio-Rad). PCR conditions and specific oligonucleotide primer pairs were those from Kobayashi et al. [27] and Guillaumie et al. [40]. The amplification efficiencies were determined by serial dilutions and normalized expression of each gene was calculated using the Bio-Rad CFX Manager software. Amplifications of the VviGAPDH and VviActin genes were used for normalization by comparing the cycle threshold of the target gene with those of standard genes. All experiments were performed with three biological replicates and two technical replicates.

\section{RNA-seq library construction and sequencing}

Grape berry mRNA was purified using oligo (dT) magnetic beads and fragmented using divalent cations at $94{ }^{\circ} \mathrm{C}$ for $8 \mathrm{~min}$. mRNA was cleaved into short fragments of about $200 \mathrm{bp}$ and double strand cDNA was synthetized using random primers and DNA polymerase I. The double stranded cDNA fragments were blunted using T4 DNA polymerase, Klenow DNA polymerase and T4 PNK. A single 'A' nucleotide was added to the 3' ends of the blunt DNA fragments using a Klenow fragment enzyme. Sequencing adaptors were ligated to the fragments that were enriched by PCR amplification (TruSeq ${ }^{\text {Tu }}$ RNA Sample Preparation v2 kit, Illumina Inc.). Surplus PCR primers were removed by purification using AMPure XP beads (Agencourt Biosciences Corporation). DNA libraries were checked for quality and quantified using 2100 Bioanalyzer (Agilent). The grape berry cDNA library products were ready for sequencing analysis via Illumina Hiseq 2500. The RNA-seq library construction and sequencing was realized by the platform "Biopuces et Sequençage" in Strasbourg, France.

\section{Analysis of Illumina reads}

Reads were mapped onto the $12 \mathrm{X}$ assembly of the Vitis vinifera genome (http://genomes.cribi.unipd.it/DATA/GEN OME_12X/Genome12X.tar.gz), using TopHat v2.0.10 [41] and the Bowtie2 v2.1.0 aligner [42]. Only uniquely aligned reads have been retained for analysis. Quantification of gene expression was performed using HTSeq v0.5.4p3 [43] with the intersection nonempty mode and CRIBI V1 annotations. The gene expression level was calculated by using RPKM (reads per exon kilo base per million mapped sequence reads).

Statistical analysis was performed using the method proposed by Love et al. [44] and implemented in the DESeq2 Bioconductor library (DESeq2 v1.0.19). Adjustment for multiple testing was performed with the Benjamini and Hochberg method [45]. The $\log _{2}$ (Fold-Change) (LFC) was estimated using the method proposed by Love et al. [44]. Genes of interest were defined by their bin code from Ath_AGI_TAIR9_Jan2010 using MapMan interface [46]. Best identity descriptions of genes were defined from annotation results available on the CRIBI website (http://genomes.cribi.unipd.it/DATA) and from Ath_AGI_ TAIR9_Jan2010 using MapMan interface. Differentially expressed genes with a $p$ value $\leq 0.05$ and an absolute value of LFC ratio $\geq 0.6$ were used as the thresholds to judge the significance of gene expression difference. Three biological replicates for each condition were included in this analysis. The RNA-seq dataset was deposited in the Gene Expression Omnibus (GEO), National Center for Biotechnology Information (NCBI) under the accession number GSE77895.

\section{Statistical analysis}

Statistical analysis were conducted using the statistical package of the $\mathrm{R}$ software ( $\mathrm{R}$ Development Core team, 2010). All the data are expressed as the mean average \pm standard error (SE) from four biological replicates for metabolites measurements and from three biological replicates and two technical replicates for gene expression profiling. Statistical significance was analyzed with Student's $t$ test. A value of $p$ value $\leq 0.05$ was considered to indicate statistical significance.

\section{Results \\ Vine water status}

The aim of this experimentation was to study the direct effect of $\mathrm{N}$ status on aroma potential without interference of water deficit. Irrigation was implemented to avoid water deficit stress. Vine water status was assessed during both seasons from July through September, by measuring stem water potential using a pressure chamber [32]. Stem water potential values for both vineyards are shown in Fig. 2. 


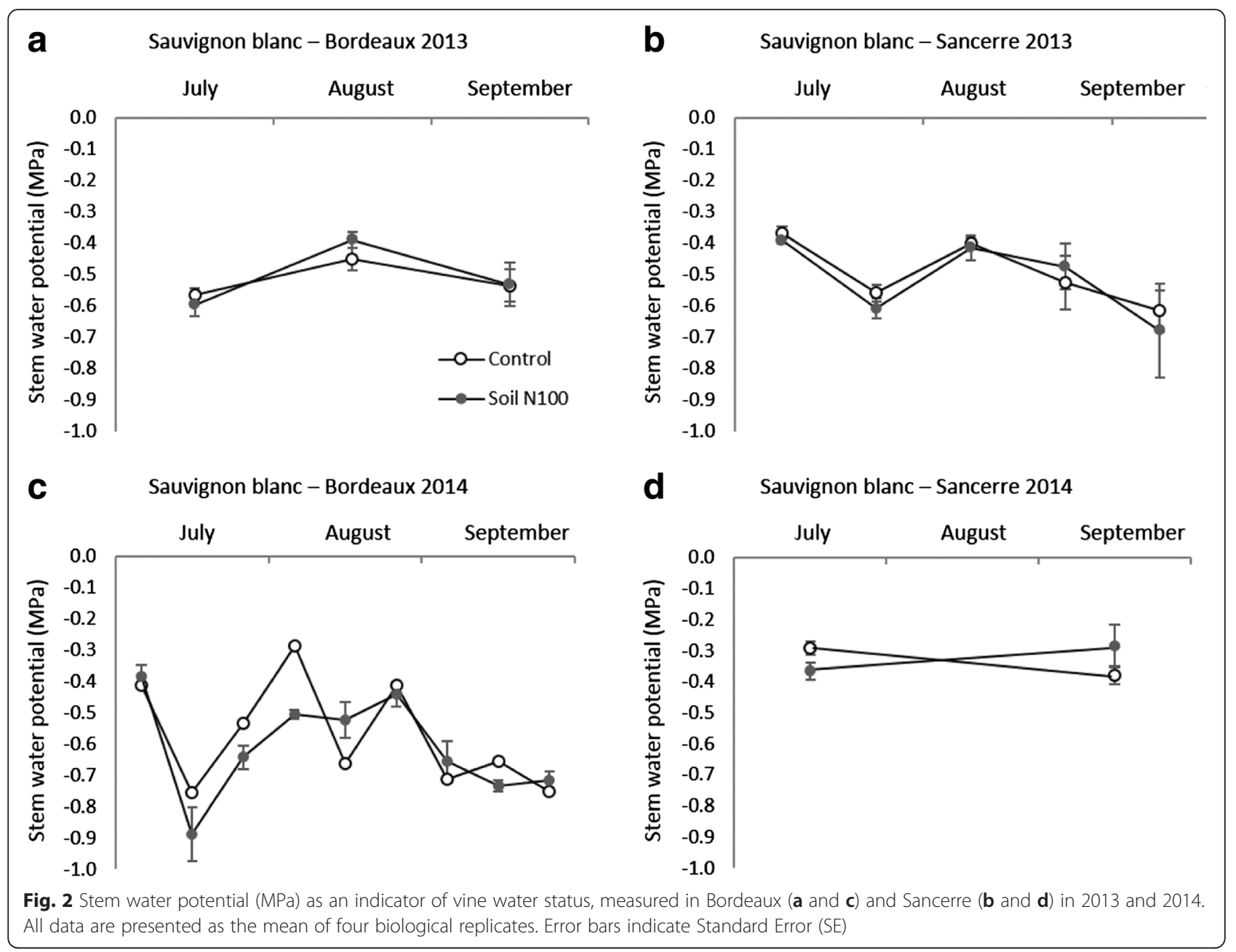

In 2013, stem water potential values ranged between $0.7 \mathrm{MPa}$ and $-0.3 \mathrm{MPa}$ and so did not exceed the threshold for water deficit of - $1 \mathrm{MPa}$. In 2014, stem water potential values ranged between $-0.95 \mathrm{MPa}$ and $0.2 \mathrm{MPa}$ in Bordeaux and -0.45 $\mathrm{MPa}$ and - 0.3 $\mathrm{MPa}$ in Sancerre. Hence, vines did not face water deficit, which allowed us to study the influence of $\mathrm{N}$ fertilization without interference with water stress.

\section{Vine vigor}

$\mathrm{N}$ supply could enhance vegetative growth and increase leaf area and yield. To limit a possible impact of $\mathrm{N}$ supply on vine vigor, the fertilization was fractionated into two doses for the soil N100 treatment and it was applied late in the season (at budbreak and at bloom). Vine vigor was estimated by measuring primary and secondary leaf areas at shoot growth cessation and by yield assessment at harvest (Table 1).

In Bordeaux, in both years, primary leaf areas for the control and for the soil N100 treatment were similar. No differences were recorded for secondary leaf area in this region either. In Sancerre, N supply did not influence primary leaf area in 2013 while it was slightly increased in 2014. Furthermore, a difference was observed for secondary leaf area in this region in both years. Soil N100 treatment developed greater leaf area compared to the control.

Yields at harvest were determined for both treatments in both vineyards. For each year and location, no significant differences of yield were observed between the N100 treatment and the control (Table 1).

Hence, vine $\mathrm{N}$ status did not modify vine vigor in the Bordeaux experiment in both years. In the Sancerre experiment, vine vigor was slightly increased, as shown by a greater secondary leaf area in the soil N100 treatment compared to the control in both years.

\section{Vine and berry nitrogen status}

Vine and berry $\mathrm{N}$ status were assessed in order to check if this nutrient was correctly assimilated in the fertilized vines. Vine $\mathrm{N}$ status determined by $\mathrm{N}$-tester measurements was higher for soil N100 treatment compared to the control during the whole season in both regions and years (Fig. 3). Differences were statistically significant for all measurements. 
Table 1 The influence of $\mathrm{N}$ supply on primary and secondary leaf areas $\left(\mathrm{m}^{2}\right.$ vine $\left.\mathrm{e}^{-1}\right)$ measured at shoot growth cessation and yield $\left(\mathrm{kg}\right.$ vine $^{-1}$ ) determined at harvest in 2013 and 2014

\begin{tabular}{|c|c|c|c|c|c|c|}
\hline & \multicolumn{3}{|l|}{ Bordeaux } & \multicolumn{3}{|l|}{ Sancerre } \\
\hline & Primary leaf area & Secondary leaf area & Yield & Primary leaf area & Secondary leaf area & Yield \\
\hline \multicolumn{7}{|l|}{2013} \\
\hline Control & $1.11^{\mathrm{a}}$ & $1.02^{\mathrm{a}}$ & $1.18^{\mathrm{a}}$ & $1.59^{a}$ & $0.59^{a}$ & $1.44^{\mathrm{a}}$ \\
\hline Soil N100 & $1.18^{a}$ & $1.30^{\mathrm{a}}$ & $1.24^{a}$ & $1.69^{a}$ & $0.95^{b}$ & $1.47^{\mathrm{a}}$ \\
\hline \multicolumn{7}{|l|}{2014} \\
\hline Control & $1.06^{\mathrm{a}}$ & $1.21^{\mathrm{a}}$ & $1.24^{\mathrm{a}}$ & $1.63^{\mathrm{a}}$ & $0.56^{a}$ & $2.57^{\mathrm{a}}$ \\
\hline Soil N100 & $1.18^{a}$ & $1.43^{\mathrm{a}}$ & $1.10^{\mathrm{a}}$ & $1.76^{b}$ & $1.37^{b}$ & $2.39^{\mathrm{a}}$ \\
\hline
\end{tabular}

Values are means of four replicates. In case of significant differences between the two treatments, different letters within the same parameter indicate significant differences. Statistical significance was determined by Student's $t$ test $(p$ value $\leq 0.05)$

Differences among treatments were confirmed by YAN measurements prior to commercial harvest. In both years and locations, YAN was always significantly higher in the N100 treatment compared to the control (Fig. 4).
Grape berries maturity and must composition

The effect of N supply on Sauvignon blanc grape berry and must composition was investigated to determine if the rate of maturity of berries was affected by the fertilization (Table 2). Grape maturity was estimated by

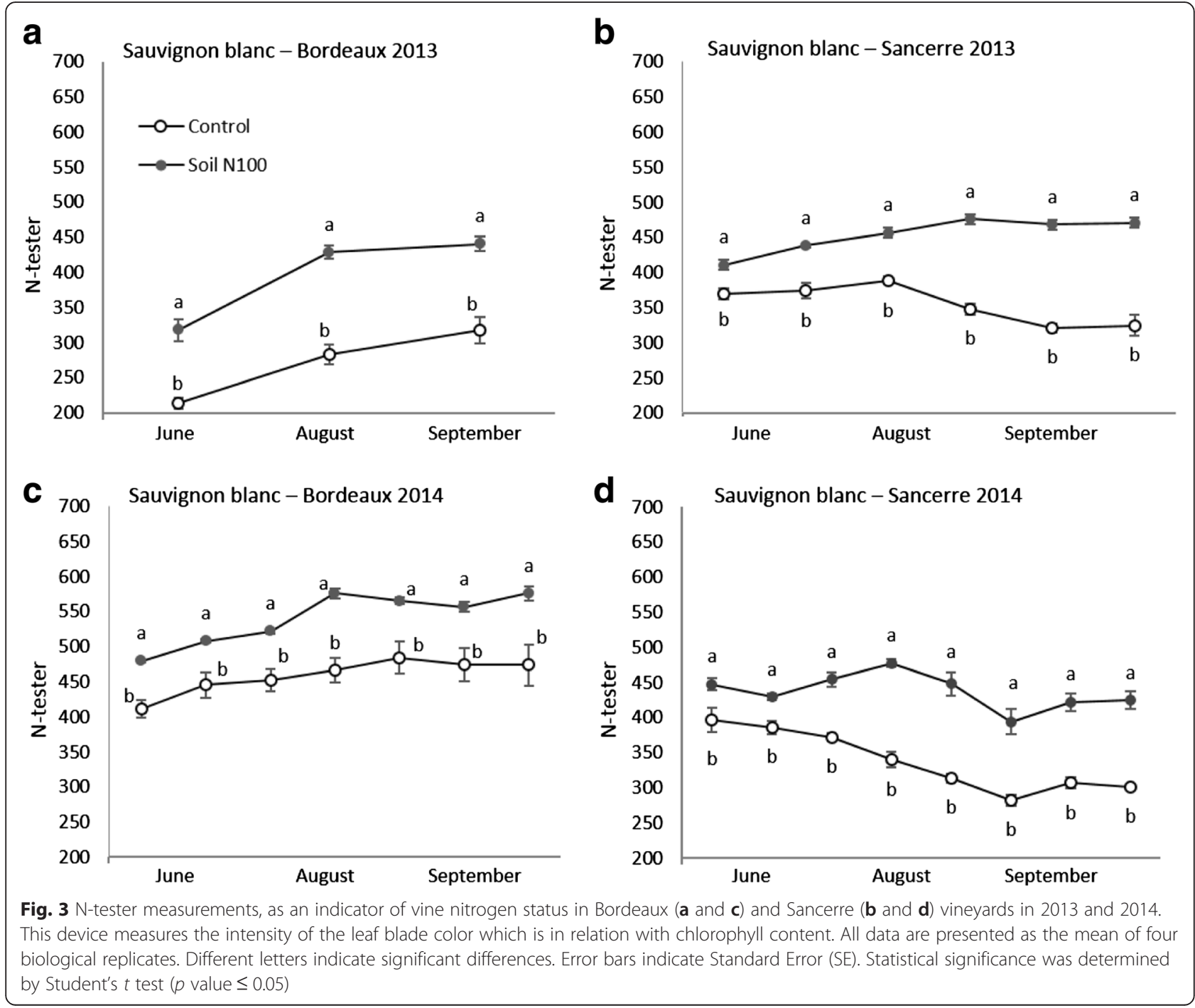



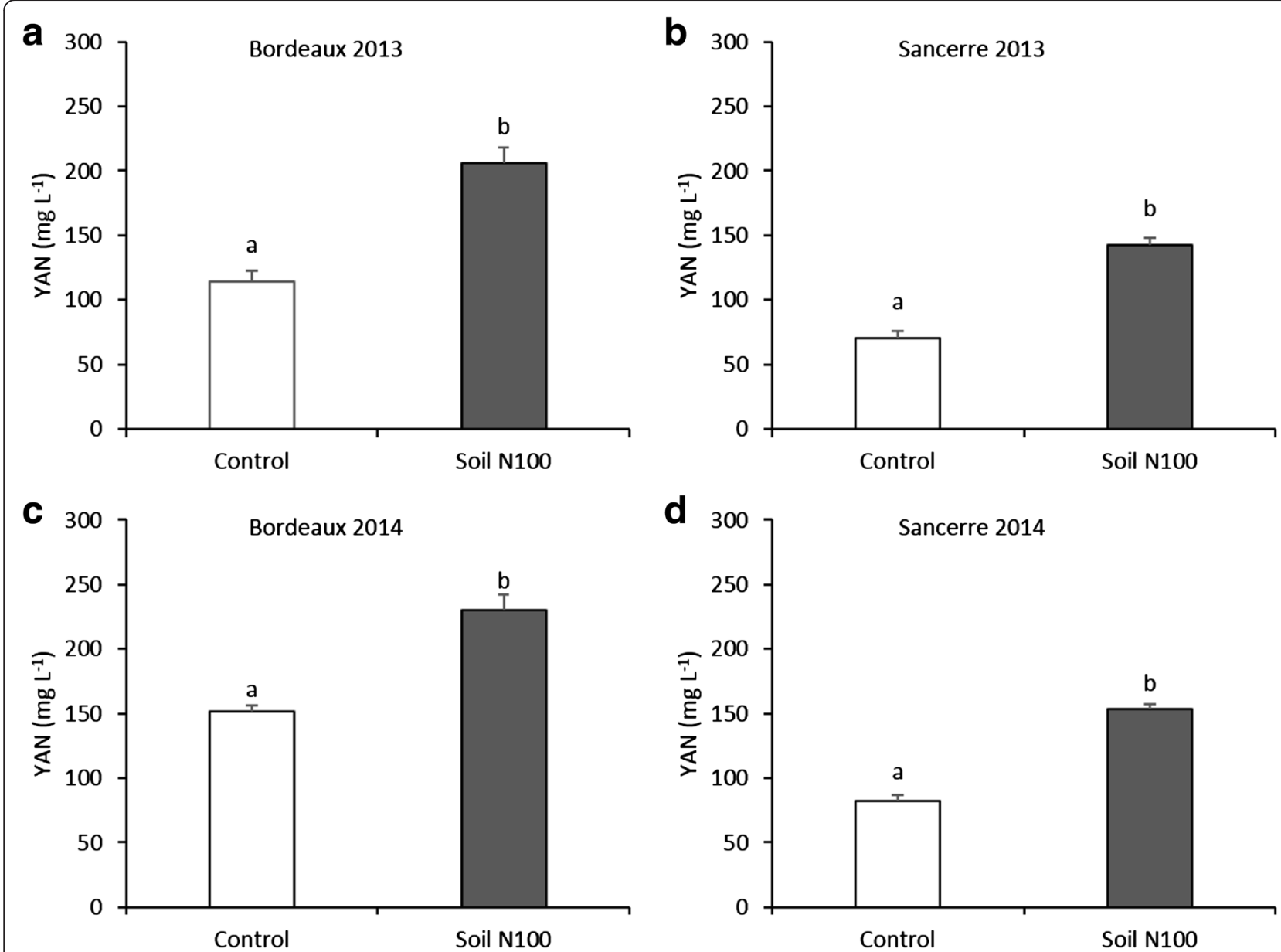

Fig. 4 Yeast Available Nitrogen (YAN) determined for each plot in 2013 and 2014 prior to commercial harvest (mg L $\mathrm{L}^{-1}$ ). All data are presented as mean of four biological replicates. Different letters indicate significant differences. Error bars indicate Standard Error (SE). Statistical significance was determined by Student's $t$ test $(p$ value $\leq 0.05)$. The white and grey bars represent the control and the soil N100 treatment respectively

measuring berry weight, sugars (glucose and fructose) and malic acid content at ripeness.

In the present study, vine $\mathrm{N}$ status did not effect berry weight except for Bordeaux in 2013 where berry weight was higher in the soil N100 treatment (Table 2). It should be noted that this difference, although statistically significant, is not relevant from an enological point of view. The concentration of berry sugars (glucose and fructose) were similar among the two treatments, except in Bordeaux in 2013 where a difference of approximately $15 \mathrm{mg} \mathrm{L}{ }^{-1}$ of glucose and fructose was observed between the control and the

Table 2 Nitrogen effect on berry weight (in gberry ${ }^{-1}$ ), sugars (glucose and fructose) and malic acid contents (in $\mathrm{mg} \mathrm{g}^{-1}$ of fresh material) measured just prior to harvest

\begin{tabular}{|c|c|c|c|c|c|c|c|c|}
\hline & \multicolumn{4}{|l|}{ Bordeaux } & \multicolumn{4}{|l|}{ Sancerre } \\
\hline & Berry weight & Glucose & Fructose & Malic acid & Berry weight & Glucose & Fructose & Malic acid \\
\hline \multicolumn{9}{|l|}{2013} \\
\hline Control & $1.62^{a}$ & $112.8^{a}$ & $111.1^{\mathrm{a}}$ & $4.3^{a}$ & $1.49^{a}$ & $100.6^{a}$ & $96.4^{a}$ & $3.1^{\mathrm{a}}$ \\
\hline Soil N100 & $1.79^{b}$ & $98.4^{b}$ & $97.2^{b}$ & $5.1^{b}$ & $1.59^{a}$ & $106.4^{\mathrm{a}}$ & $105.4^{\mathrm{a}}$ & $3.9^{b}$ \\
\hline \multicolumn{9}{|l|}{2014} \\
\hline Control & $2.26^{a}$ & $82.9^{a}$ & $81.1^{\mathrm{a}}$ & $3.4^{\mathrm{a}}$ & $1.89^{\mathrm{a}}$ & $82.2^{\mathrm{a}}$ & $76.6^{a}$ & $4.2^{a}$ \\
\hline Soil N100 & $2.18^{a}$ & $79.1^{a}$ & $77.5^{\mathrm{a}}$ & $4.4^{b}$ & $1.96^{\mathrm{a}}$ & $83.9^{a}$ & $78.9^{a}$ & $4.6^{b}$ \\
\hline
\end{tabular}

Values are means of four replicates. In case of significant differences between the two treatments, different letters within the same parameter indicate significant differences. Statistical significance was determined by Student's $t$ test $(p$ value $\leq 0.05)$ 
fertilized modality. Malic acid was always lower in the control compared to N100 treatment. Differences ranged from $0.4 \mathrm{mg} \mathrm{g}^{-1}$ (Sancerre 2014) to $1.0 \mathrm{mg} \mathrm{g}^{-1}$ (Bordeaux 2014).

The effect of $\mathrm{N}$ addition on sugar and malic acid content, $\mathrm{pH}$ and acidity was also measured in grape must just prior to commercial harvest (Table 3). No effect of $\mathrm{N}$ fertilization was noticed on sugar level in Bordeaux in 2013 and Sancerre in 2014. A decrease of $16 \mathrm{~g} \mathrm{~L}^{-1}$ and $5 \mathrm{~g} \mathrm{~L}^{-1}$ in sugar content was observed in soil N100 treatment in Bordeaux in 2014 and Sancerre in 2013 respectively. $\mathrm{pH}$ was not impacted by the fertilization and only in Bordeaux in 2014 an increase of $0.6 \mathrm{~g}$ tartrate eq. $\mathrm{L}^{-1}$ in total acidity was observed. In Bordeaux in both years and in Sancerre in 2014, malic acid concentration was higher in berries harvested in soil N100 treatment. In Bordeaux, differences in malic acid level between the two treatments were in the order of $1.3 \mathrm{~g} \mathrm{~L}^{-1}$ and $0.7 \mathrm{~g} \mathrm{~L}^{-1}$ in 2013 and 2014 respectively while in Sancerre in 2014, an increase of $0.4 \mathrm{~g} \mathrm{~L}^{-1}$ was measured in the N100 treatment. Grape ripening was delayed by N fertilization, as shown by decreased sugar concentrations and/or increased malic acid concentrations. However, although these differences are statistically significant, they correspond to a delay in ripeness of only 2-4 days, depending on location and year. Difference did not seem great enough to justify different sampling dates for maturity for the control versus the soil N100 treatment.

\section{Nitrogen effect on thiol level in wines}

The effect of $\mathrm{N}$ fertilization on $3 \mathrm{SH}$ and 4MSP in Sauvignon blanc wine from Bordeaux and Sancerre was investigated in 2013 and 2014 (Fig. 5). Higher levels of 3SH were recorded in 2013 compared to 2014 in both vineyards. The concentration of $3 \mathrm{SH}$ was particularly high in Sancerre in 2013, where it reached $2198 \mathrm{ng} \mathrm{L}^{-1}$ for the soil N100 treatment versus $570 \mathrm{ng} \mathrm{L}^{-1}$ in Bordeaux for the same modality. As for 3SH, 4MSP level was the highest in Sancerre in 2013 where concentrations ranged between 110 and $115 \mathrm{ng} \mathrm{L}^{-1}$.

Concerning the impact of $\mathrm{N}$ supply on these volatile thiols, wines made from berries grown on fertilized vines had higher $3 \mathrm{SH}$ concentration than those made from berries grown on non-fertilized vines, although this difference was not significant in Bordeaux in 2013 (Fig. 5a). For example, compared to control plants, $3 \mathrm{SH}$ level in the soil N100 treatment was 2.5-fold higher in Sancerre in 2013 (2198 $\mathrm{ng} \mathrm{L}^{-1}$ versus $911 \mathrm{ng} \mathrm{L}^{-1}$ ), 1.5-fold higher in Sancerre in $2014\left(299 \mathrm{ng} \mathrm{L}^{-1}\right.$ versus $\left.201 \mathrm{ng} \mathrm{L}^{-1}\right)$ and 3.5-fold higher in Bordeaux in 2014 (429 $\mathrm{ng} \mathrm{L}^{-1}$ versus $123 \mathrm{ng} \mathrm{L}^{-1}$ ). No significant differences were observed on 4MSP levels between the two treatments in all combinations. Hence, vine $\mathrm{N}$ status does not influence 4MSP contents in Sauvignon blanc wines (Fig. 5b). For this reason, 4MSP and its precursors were not further investigated in this study.

\section{Nitrogen effect on Glut-3SH and Cys-3SH contents in grape berries}

To determine the effect of $\mathrm{N}$ supply on the glutathionylated (Glut-3SH) and the cysteinylated (Cys-3SH) precursors of 3SH in Sauvignon blanc berries, their content in the control and in the soil N100 treatment was monitored during three developmental stages, at midveraison $(v)$, mid-ripening $(v+28)$ and ripeness $(v+35)$ (Fig. 6).

Glut-3SH concentration increased during berry ripening and reached a peak at $(v+35)$ except for Bordeaux in 2014 where the highest value was attained at $(v+28)$. Glut-3SH content was related to vine $\mathrm{N}$ status. Although statistically not always significant, Glut-3SH level was in general higher in the soil N100 treatment compared to the control in all combinations (Fig. 6a-d). For example in Bordeaux in 2013 at $(v+35)$, Glut-3SH content was 10 -fold higher in the N100 treatment $\left(35.75 \mu \mathrm{g} \mathrm{L}^{-1}\right.$ versus $3.5 \mu \mathrm{g} \mathrm{L}^{-1}$ respectively, Fig. 6a) than in the control. In the same year in Sancerre at $(v+28)$, the content of the glutathionylated precursor in the N100 treatment

Table 3 The effect of nitrogen addition on sugar level $\left(\mathrm{g} \mathrm{L}^{-1}\right)$, Total Acidity $\left(\mathrm{g}\right.$ tartrate eq. $\left.\mathrm{L}^{-1}\right)$, $\mathrm{pH}$ and malic acid content $\left(\mathrm{g} \mathrm{L}^{-1}\right)$ in grape musts prior to harvest in 2013 and 2014

\begin{tabular}{|c|c|c|c|c|c|c|c|c|}
\hline & \multicolumn{4}{|c|}{ Bordeaux } & \multicolumn{4}{|c|}{ Sancerre } \\
\hline & Sugar & Total Acidity & $\mathrm{pH}$ & Malic acid & Sugar & Total Acidity & $\mathrm{pH}$ & Malic acid \\
\hline \multicolumn{9}{|l|}{2013} \\
\hline Control & $193^{a}$ & $10.9^{a}$ & $2.99^{a}$ & $4.7^{\mathrm{a}}$ & $205^{a}$ & $7.9^{\mathrm{a}}$ & $3.17^{a}$ & $3.8^{a}$ \\
\hline Soil N100 & $174^{a}$ & $11.7^{\mathrm{a}}$ & $3.01^{\mathrm{a}}$ & $6.0^{a}$ & $190^{b}$ & $7.6^{a}$ & $3.20^{\mathrm{a}}$ & $3.8^{a}$ \\
\hline \multicolumn{9}{|l|}{2014} \\
\hline Control & $204^{a}$ & $10.8^{a}$ & $3.08^{a}$ & $5.1^{\mathrm{a}}$ & $205^{\mathrm{a}}$ & $9.0^{a}$ & $3.05^{a}$ & $4.6^{a}$ \\
\hline Soil N100 & $198^{b}$ & $11.4^{b}$ & $3.10^{a}$ & $5.8^{b}$ & $204^{a}$ & $9.4^{a}$ & $3.07^{a}$ & $5.1^{b}$ \\
\hline
\end{tabular}

Values are means of four replicates. In case of significant differences between the two treatments, different letters within the same parameter indicate significant differences. Statistical significance was determined by Student's $t$ test $(p$ value $\leq 0.05)$ 


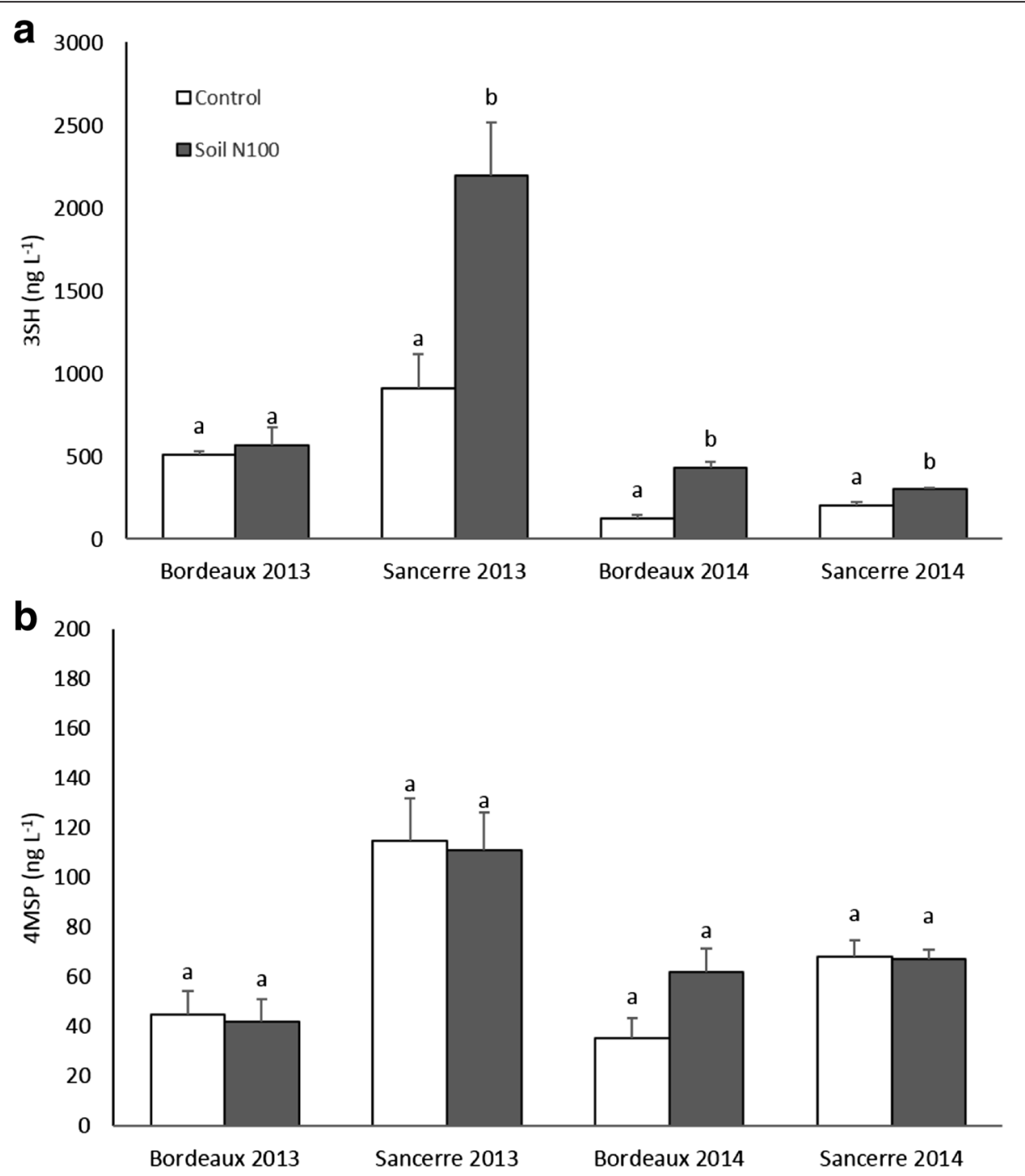

Fig. 5 Effects of nitrogen supply on the level of $(\mathbf{a}) 3 \mathrm{SH}\left(\mathrm{ng} \mathrm{L}^{-1}\right)$ and (b) 4MSP $\left(n \mathrm{~L} \mathrm{~L}^{-1}\right)$ in wines made by small-scale vinifications. All data are presented as mean of four biological replicates. Different letters indicate significant differences. Error bars indicate Standard Error (SE). Statistical significance was determined by Student's $t$ test $(p$ value $\leq 0.05$ )

was 5 -fold higher than in the control $\left(3.1 \mu \mathrm{g} \mathrm{L} \mathrm{L}^{-1}\right.$ versus $15.2 \mu \mathrm{g} \mathrm{L}{ }^{-1}$, Fig. 6b).

Cys-3SH was only detectable in Bordeaux and Sancerre in 2013 (Fig. 6e-f). In 2014 in both areas, its level was below the detection limits of the method $\left(\mathrm{LOQ}=0.5 \mu \mathrm{g} \mathrm{L}^{-1}\right)$. The concentration of Cys-3SH was relatively low and stable in the subsequent developmental stages. Moreover the content of this molecule was similar between the control and the soil N100 treatment, indicating that vine $\mathrm{N}$ status did not influence Cys-3SH content in Sauvignon blanc grape berries.

\section{Nitrogen effect on Glut-3SH and Cys-3SH contents in musts} Analyzing $3 \mathrm{SH}$ precursors in grape musts is important due to the fact that those precursors will be transformed in $3 \mathrm{SH}$ during the alcoholic fermentation. Several enological techniques like destemming, crushing, pressing and clarification may influence their level during must preparation before fermentation. The glutathionylated and the cysteinylated precursors of $3 \mathrm{SH}$ were assessed in Bordeaux and Sancerre Sauvignon blanc musts at harvest in 2013 and 2014 (Fig. 7). Compared to berries, concentrations of Glut-3SH and Cys-3SH were approximately 20fold higher in the corresponding must demonstrating that important amounts of precursors in the must are synthesized during the pre-fermentation operations. Differences may also result from the technology of grape processing: immediate freezing in liquid nitrogen for grape berries versus pressing at room temperature to obtain grape must or from the way of grape pressing. Musts from Sancerre were in most cases richer in these precursors compared to musts from Bordeaux. 


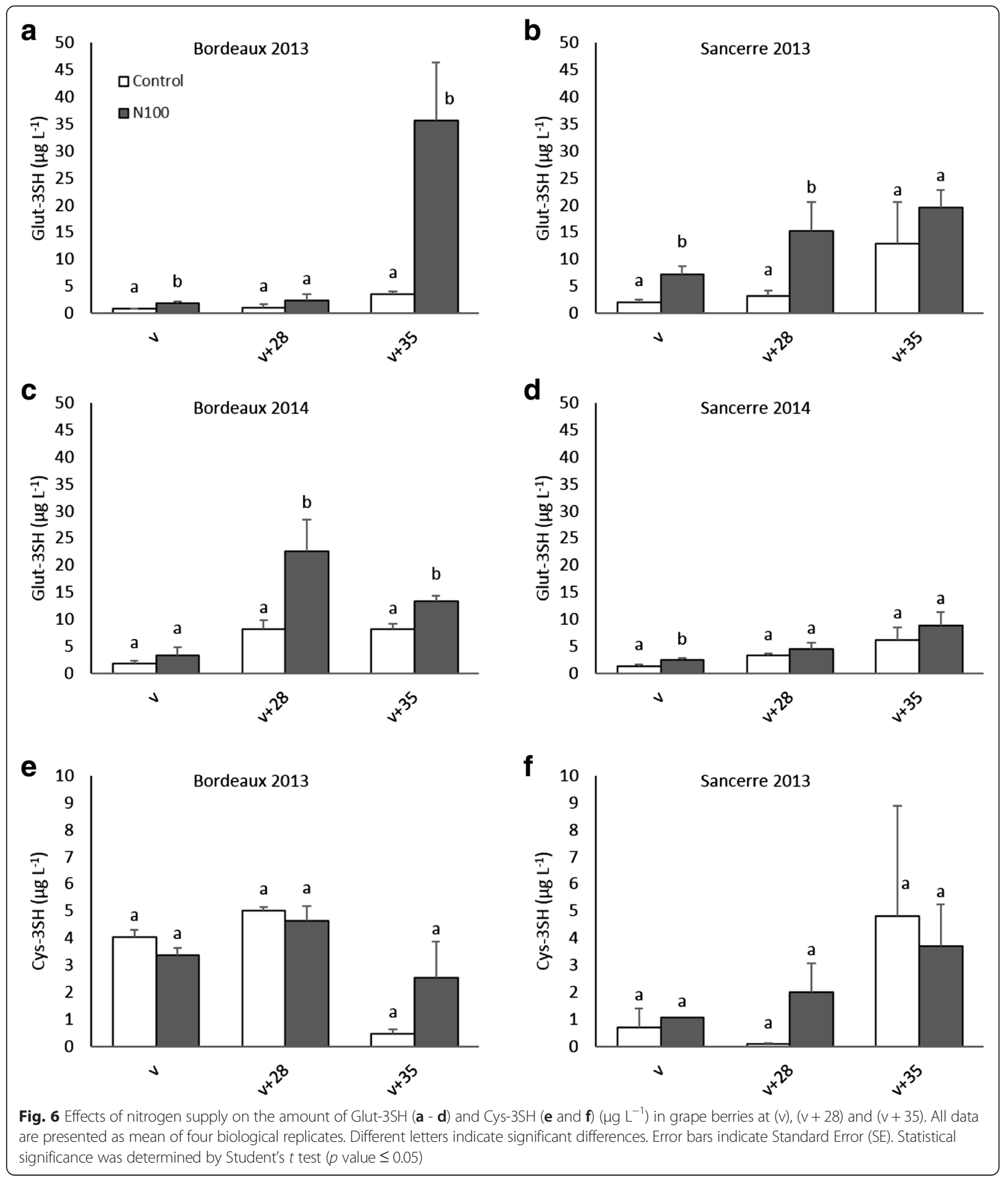

The fertilization led to a significant increase in the concentration of Glut-3SH in 2013 in both vineyards (Fig. 7a-b). Levels of Glut-3SH in the control were in order of $91 \mu \mathrm{g} \mathrm{L}^{-1}$ in Bordeaux and $328 \mu \mathrm{g} \mathrm{L}^{-1}$ in Sancerre and they increased to $178 \mu \mathrm{g} \mathrm{L}^{-1}$ and $544 \mu \mathrm{g} \mathrm{\textrm {L } ^ { - 1 }}$ respectively in the soil N100 treatment. In 2014 in both regions, only a trend for a higher Glut-3SH content was observed in the must from high $\mathrm{N}$ vines (Fig. $7 \mathrm{c}-\mathrm{d}$ ).

Levels of Cys-3SH were lower compared to Glut-3SH, which confirmed an earlier observation [47-49]. In both 


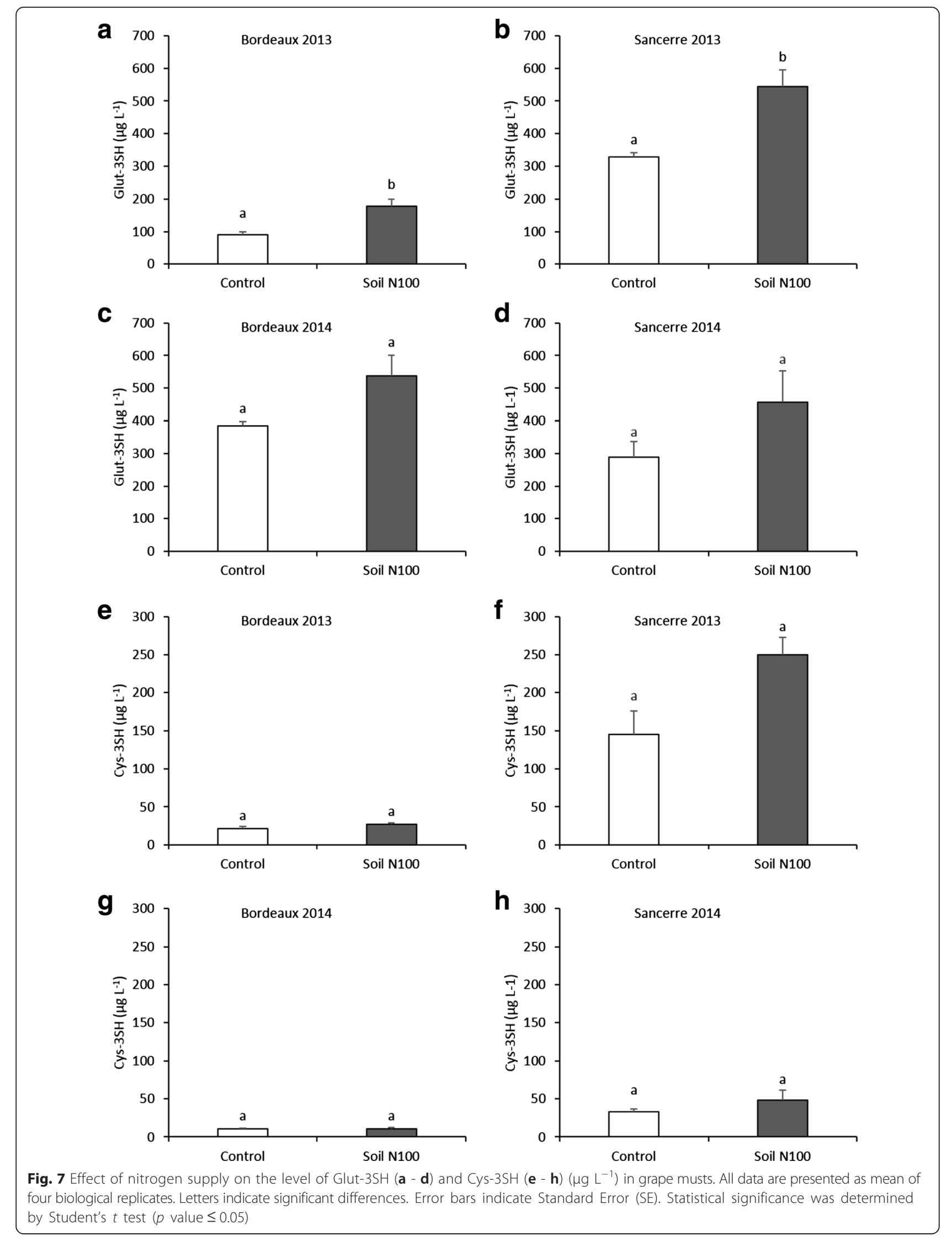


years, vine $\mathrm{N}$ status did not affect Cys-3SH level (Fig. 7e-h). In Bordeaux, Cys-3SH content ranged between $21 \mu \mathrm{g} \mathrm{L}^{-1}$ and $27 \mu \mathrm{g} \mathrm{L}^{-1}$ in 2013 while in 2014 it was in the order of $11 \mu \mathrm{g} \mathrm{L}{ }^{-1}$. In Sancerre, Cys-3SH level was particularly high in 2013 where values ranged between $145 \mu \mathrm{g} \mathrm{L}^{-1}$ and $250 \mu \mathrm{g} \mathrm{L}^{-1}$. In the same year, the $3 \mathrm{SH}$ content in Sancerre wines was very high, which confirms a positive relation between the abundance of the precursors in the must and the abundance of the corresponding thiol in the wine. In 2014, the concentration of this molecule was in the same range as in Bordeaux with values comprised between 30 and $45 \mu \mathrm{g} \mathrm{L}^{-1}$.

These results showed that higher vine and berry $\mathrm{N}$ status increased the content of the glutathionylated precursor of 3SH in Sauvignon blanc grapes and musts while the concentration of the cysteinylated precursor was not affected.

\section{Gene expression from the 3SH pathway and their response to nitrogen fertilization}

In a study published in 2011 [27], Kobayashi et al. described two genes, VviGST3 and VviGST4, from the family of the glutathione-S-transferases, as essential genes in the biosynthetic pathway of $3 \mathrm{SH}$. These genes are responsible for the addition of the glutathione to the trans-2-hexanal to produce the Glut-3SH. Another gene, $V v i G G T$, responsible for the conversion of Glut-3SH to Cysgly-3SH, an intermediate precursor, was also identified [27]. The expression profile of these three genes and of $V v i N i R$, a gene from the $\mathrm{N}$ assimilation pathway at vine roots level which serves as a positive control for vine $\mathrm{N}$ status [50], was determined in Sauvignon blanc berries from Bordeaux at different developmental stages (Fig. 8).

The VviNiR expression profile increased in 2013 during ripening and reached a maximum at $(\mathrm{v}+35)$ stage. $\mathrm{N}$ supply resulted in an increasing of $V v i N i R$ transcript levels and differences were statistically significant at (v-20), an early developmental stage and at $(v+35)$ (Fig. 8a). In 2014, the expression of $V v i N i R$ increased with berry development and peaked at $(\mathrm{v}+28)$. As for 2013, $\mathrm{N}$ increased transcript abundance of this gene mainly at ( $v-20)$ (Fig. 8b).

VviGST3 and VviGST4 expression profiles were also studied during grape ripening. In 2013 and 2014, for both treatments, the relative expression of VviGST3 increased during ripening. It was 3-fold higher at $(v+35)$ compared to (v-20) (Fig. 8c-d). As for VviGST3, VviGST4 had the same profile in 2013 and 2014 when its expression increased during the season (Fig. 8e-f). The transcript abundance of VviGGT was also similar in both years. It was low at $(\mathrm{v}-20)$ compared to the two other stages where it was to a large extent stable: the expression of $V v i G G T$ was 2-fold higher at $(\mathrm{v}+35)$ compared to (v-20) (Fig. 8g-h). No significant differences were observed in the expression of VviGST3, VviGST4 and VviGGT genes between the control and the soil N100 treatment at all stages in both years.

Furthermore, the expression profiles of these genes were also investigated in the RNA-seq data. In 2013, the expression profile of VviNiR (VIT_03s0063g00370) was modified in response to nitrogen (LFC 0.78 and 0.60 at $(\mathrm{v}+28)$ and $(\mathrm{v}+35)$ respectively, Additional file 1). Moreover, two other genes, a nitrate transporter-like (VIT_01s0026g01570) and a nitrite transporter-like (VIT_01s0011g03400) responded to N supply. The expression of the first one was up-regulated by this nutrient at $(\mathrm{v}+28)$ and $(\mathrm{v}+35)$ (LFC 0.71 and 0.92 respectively) while the expression of the second gene was down-regulated by $\mathrm{N}$ and it was significant only at $(\mathrm{v}+35)(\mathrm{LFC}-0.63)$. In 2014, none of these genes were affected by N. Both in 2013 and 2014, the transcripts of VviGST3, VviGST4 and VviGGT were not affected by $\mathrm{N}$ supply confirming results obtained by the qRT-PCR. Hence, these genes are clearly not regulated by nitrogen.

\section{Identification of candidate genes from the biosynthetic pathway of $3 \mathrm{SH}$ precursors}

Only the genes differentially expressed in response to $\mathrm{N}$ supply were investigated, due to their potential implication in differences observed on Glut-3SH level between $\mathrm{N}$ treatments. Two strategies were conducted in order to identify new candidate genes from the biosynthetic pathway of 3SH precursors. The first one, a "targeted approach", consisted in searching genes from families already described in the literature as implicated in the pathway. The second one, an "untargeted approach", consisted in a screening of all common genes between $(\mathrm{v}+28)$ and $(\mathrm{v}+35)$ stages, when $\mathrm{N}$ effect on Glut-3SH was observed, and which are differentially expressed between the control and the soil N100 treatment.

For the "targeted approach", we referred to the pathway already described by Kobayashi et al. [21] and Thibon et al. [22] where a glutathione- $S$-transferase (GST), a $\gamma$-glutamyltranspeptidase (GGT) and a carboxypeptidase were assumed to be essential for generating the precursors.

According to the National Center for Biotechnology Information reference sequence (NCBI RefSeq, August 03, 2015) database, 118 genes encoding GST enzymes were identified in Vitis vinifera. Of these genes, in 2013, 94 GST transcripts at $(\mathrm{v}+28)$ and 96 at $(\mathrm{v}+35)$ were detected in our RNA-seq dataset. In 2014, 97 and 102 GST transcripts were expressed at $(\mathrm{v}+28)$ and $(\mathrm{v}+35)$ respectively. VviGSTs with $p$ value $\leq 0.05$ and $\mid$ LFC $\mid \geq 0.6$ were considered to respond to $\mathrm{N}$ supply and might be involved in differences observed on Glut-3SH level among 


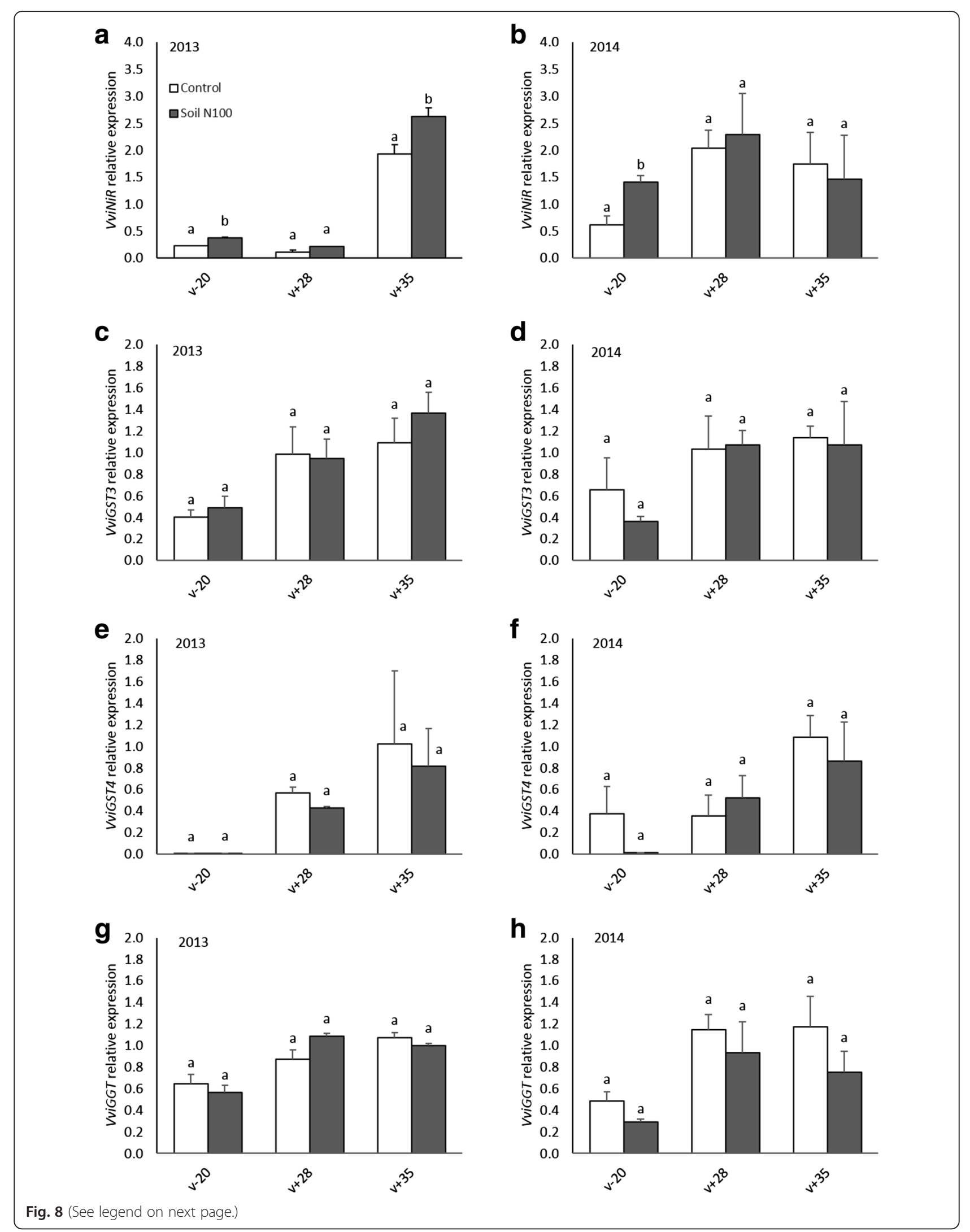


(See figure on previous page.)

Fig. 8 Changes in relative transcript levels of genes of VViNiR, VVIGST3, VViGST4 and VViGGT in grape berries throughout their development in the Bordeaux experimental site. Transcript levels were analyzed by real-time PCR and are shown relative to expression of VviGAPDH and VviActin in each sample. All data are presented as mean of three biological replicates and two technical replicates. Letters indicate significant differences. Error bars indicate Standard Error (SE). Statistical significance was determined by Student's $t$ test ( $p$ value $\leq 0.05)$. The white and grey bars represent the control and the soil N100 treatment respectively. (v-20), 20 days before mid-veraison; $(v+28)$, mid-ripening; $(v+35)$, ripeness

treatments. A list of these VviGSTs is given in Table 4. In 2013, at $(v+28)$, VIT_19s0015g02680 was 2-fold upregulated in the soil N100 treatment compared to the control. At this same developmental stage, 2 other GSTs, VIT_16s0039g01070 and VIT_07s0104g01800 were 1.7-fold and 1.8-fold up-regulated in the fertilized modalities (Table 4a).

VviGSTs identified at $(\mathrm{v}+35)$ were different from those described at $(\mathrm{v}+28)$. At this stage, VIT_01s0026g02400, VIT_06s0004g05680 and VIT_19s0015g02690 were found to be up-regulated in the fertilized vines compared to the control. However, VIT_12s0035g02100 expression profile was down-regulated by $\mathrm{N}$ supply (Table 4a). All identified $V v i G S T s$ were from the tau family (GSTU) except for VIT_07s0104g01800 and VIT_12s0035g02100 which are from phi (GSTF) and zeta (GSTZ) family respectively.

In 2014, no VviGST were differentially expressed between the control and the soil N100 treatment at both developmental stages.

The $3 \mathrm{SH}$ precursor pathway involves also the presence of a GGT and a carboxypeptidase. Eleven VviGGTs were identified in 2013 and 2014 at both stages but using the same criteria as for VviGSTs ( $p$ value $\leq 0.05$ and $\mid$ LFC $\mid \geq 0.6)$, none was differentially expressed between fertilized and unfertilized vines.

Concerning the large family of carboxypeptidases, 1453 at $(v+28)$ and 1431 at $(v+35)$ were expressed in the RNA-seq data. Among these carboxypeptidases, in 2013, 15 at $(v+28)$ and 20 at $(v+35)$ had a different expression pattern among treatments. Except for 4 at $(v+28)$ and 5 at $(v+35)$, all the identified carboxypeptidases were upregulated by $\mathrm{N}$ (Table $4 \mathrm{a})$. In 2014 , at $(v+28)$, none of these carboxypeptidases was regulated by vine $\mathrm{N}$ status. At $(v+35)$, only one (VIT_14s0066g01950) was downregulated in response to this nutrient (Table $4 \mathrm{~b}$ ).

For the "untargeted method", all genes affected by $\mathrm{N}$ supply at $(v+28)$ and $(v+35)$ were identified (Fig. 9). As represented in the Venn diagram, in 2013, 305 genes were up-regulated and 95 genes were downregulated by $\mathrm{N}$ at $(\mathrm{v}+28)$. In this category, the most represented families belong to stress, DNA, signaling, metal handling and secondary and amino acid metabolisms (Additional file 1). At $(v+35), 131$ genes were stimulated by $\mathrm{N}$ while 225 were repressed. At this developmental stage, GO related to photosystem, secondary metabolism, cell wall, biodegradation of xenobiotics, development and DNA were the most represented (Additional file 1). Between the 2 stages, 107 common up-regulated genes and 13 downregulated genes were identified (Fig. 9a).

In 2014, at $(v+28), 20$ and six genes were up- and down-regulated by $\mathrm{N}$ respectively. Genes related to stress were the most represented. At $(v+35)$, the expression of 14 genes was stimulated by $\mathrm{N}$ and the expression of eight genes was repressed by this nutrient. At this stage, categories represented with the highest number of genes encompassed the stress and the secondary metabolism gene families (Additional file 2). Six up-regulated and two down-regulated genes in response to $\mathrm{N}$ were common between the 2 stages (Fig. 9b).

By combining the dataset from the 2 years, ten and two genes respectively were up-regulated and downregulated by $\mathrm{N}$ at $(\mathrm{v}+28)$. At $(\mathrm{v}+35)$, five genes were up-regulated by $\mathrm{N}$ while one was repressed. Two upregulated genes responding to $\mathrm{N}$ were common between $(v+28)$ and $(v+35)$, whereas no down-regulated genes were found in this category (data not shown). In this category, genes related to stress, hormone metabolism, RNA, protein and transport were found (Additional file 3).

We also paid special attention on genes encoding transporters given their essential role in nitrogen and secondary metabolism regulation.

In 2013, 30 and 24 genes encoding transporters responded to $\mathrm{N}$ supply at $(\mathrm{v}+28)$ and $(\mathrm{v}+35)$ respectively. They encompassed many transport process, including the transport of metals, nitrate, potassium, sulphate, calcium, sugars and amino acids. Genes involved in the transport of peptides and oligopeptides, as well as genes from the ATP binding cassette $(\mathrm{ABC})$ transporters family also belonged to the transport genes differentially regulated by N. From these genes, ten were common between the two developmental stages (Table 5a). In 2014, the expression of three genes at $(v+28)$ and two genes at $(v+35)$ was modified by $\mathrm{N}$ fertilization. These genes are involved in metal or anions transport or belong to the ABC transporter family. Only one gene was common between the two developmental stages (Table 5b).

Only genes common to both stages that were differentially expressed between the control and the N100 treatment were examined due to the fact that Glut-3SH level was modified at both stages. Within this category, in 2013, genes encoding a putative nitrate transporter (VIT_01s0026g01570), a putative zinc transporter (VIT_03s0017g02170), a putative sulfate transporter 
Table 4 Glutathione-S-transferase and carboxypeptidase genes differentially expressed between the control and the soil N100 treatment at mid-ripening $(v+28)$ or ripeness $(v+35)$ in (a) 2013 and (b) 2014

\begin{tabular}{|c|c|c|c|}
\hline \multicolumn{4}{|l|}{ A } \\
\hline \multirow[t]{2}{*}{ V1_ID } & \multirow[t]{2}{*}{ Best identity description } & \multicolumn{2}{|c|}{ LFC } \\
\hline & & $(v+28)$ & $(v+35)$ \\
\hline \multicolumn{4}{|c|}{ Putative Glutathione-S-transferase (Bincode 26.9) } \\
\hline VIT_01s0026g02400 & GSTU10-like & ns & 0.79 \\
\hline VIT_06s0004g05680 & GSTU7-like & ns & 0.68 \\
\hline VIT_07s0104g01800 & GSTF13-like & 0.87 & ns \\
\hline VIT_12s0035g02100 & GSTZ2-like & ns & -0.94 \\
\hline VIT_1650039g01070 & GSTU8-like & 0.79 & ns \\
\hline VIT_19s0015g02680 & GSTU25-like & 0.94 & ns \\
\hline VIT_19s0015g02690 & GSTU25-like & ns & 0.79 \\
\hline \multicolumn{4}{|c|}{ Putative carboxypeptidase (Bincode 29.5) } \\
\hline VIT_00s0187g00120 & $\begin{array}{l}\text { Putative cysteine protease } \\
\text { inhibitor }\end{array}$ & 0.63 & ns \\
\hline VIT_00s0265g00070 & Ubiquitin-protein ligase & -0.71 & ns \\
\hline VIT_00s0323g00100 & Cysteine-type endopeptidase & ns & -0.61 \\
\hline VIT_00s2015g00020 & F-box protein FBW2-like & 1.12 & ns \\
\hline VIT_00s2507g00010 & F-box protein FBW2-like & 2.26 & 0.81 \\
\hline VIT_01s0010g02860 & $\begin{array}{l}\text { Mitochondrial chaperone } \\
\text { BCS1-like }\end{array}$ & ns & -0.90 \\
\hline VIT_01s0011g02000 & Serine carboxypeptidase-like 35 & ns & 0.71 \\
\hline VIT_01s0137g00330 & Putative cysteine proteinase & ns & -0.93 \\
\hline VIT_01s0150g00330 & $\begin{array}{l}\text { U-box domain-containing protein } \\
\text { 43-like }\end{array}$ & ns & 0.79 \\
\hline VIT_03s0088g00260 & Serine carboxypeptidase 16-like & ns & 0.91 \\
\hline VIT_03s0091g01290 & Serine carboxypeptidase 18-like & 1.06 & 1.09 \\
\hline VIT_04s0043g00840 & Ubiquitin-protein ligase & -0.72 & ns \\
\hline VIT_05s0020g05000 & $\begin{array}{l}\text { Serine-type endopeptidase } \\
\text { inhibitor }\end{array}$ & ns & 1.46 \\
\hline VIT_06s0061g00710 & Zinc finger family protein & 0.99 & 0.87 \\
\hline VIT_06s0080g00150 & Serine-type endopeptidase & ns & 0.73 \\
\hline VIT_07s0104g00180 & $\begin{array}{l}\text { Putative extracellular dermal } \\
\text { glycoprotein }\end{array}$ & 0.67 & ns \\
\hline VIT_08s0007g00120 & Ubiquitin-protein ligase & 0.60 & ns \\
\hline VIT_08s0007g02470 & Aspartyl protease family protein & ns & 0.68 \\
\hline VIT_08s0040g01140 & Putative serine carboxypeptidase & 1.19 & ns \\
\hline VIT_08s0058g00700 & F-box family protein & ns & -0.64 \\
\hline VIT_10s0116g00560 & Polyphenol oxidase & 1.60 & 2.19 \\
\hline VIT_11s0016g03010 & Peptidase family protein & ns & 0.62 \\
\hline VIT_13s0019g05120 & Cysteine proteinase $15 \mathrm{~A}$-like & ns & -0.75 \\
\hline VIT_13s0047g00200 & Xylem serine proteinase 1 -like & ns & 0.84 \\
\hline VIT_14s0006g00180 & $\begin{array}{l}\text { Aspartic proteinase nepenthesin- } \\
\text { 2-like }\end{array}$ & -0.80 & ns \\
\hline VIT_1450219g00210 & Ubiquitin family protein & -0.74 & ns \\
\hline IIT_15s0046g02160 & Peptidase family protein & 0.64 & 0.66 \\
\hline
\end{tabular}

Table 4 Glutathione-S-transferase and carboxypeptidase genes differentially expressed between the control and the soil N100 treatment at mid-ripening $(v+28)$ or ripeness $(v+35)$ in (a) 2013 and (b) 2014 (Continued)

\begin{tabular}{|c|c|c|c|}
\hline VIT_18s0001g00510 & Serine-type endopeptidase & ns & 0.70 \\
\hline VIT_18s0041g00370 & $\begin{array}{l}\text { Cysteine proteinase inhibitor } \\
\text { 1-like }\end{array}$ & 0.85 & ns \\
\hline VIT_19s0085g01110 & Putative aspartic proteinase & ns & 1.19 \\
\hline \multicolumn{4}{|l|}{ B } \\
\hline \multirow[t]{2}{*}{ V1_ID } & \multirow[t]{2}{*}{ Best identity description } & \multicolumn{2}{|c|}{ LFC } \\
\hline & & $(v+28)$ & $(v+35)$ \\
\hline \multicolumn{4}{|c|}{ Putative carboxypeptidase (Bincode 29.5) } \\
\hline VIT_14s0066g01950 & Metalloendoproteinase 1-like & ns & -0.62 \\
\hline
\end{tabular}

(VIT_11s0016g04160) and a putative chloride transporter (VIT_14s0068g02190) were found. Two gamma tonoplast intrinsic protein (VIT_06s0061g00730 and VIT_08s0007g04780), a putative phosphoglyceride transporter (VIT_10s0003g05480) and a putative amino acid transporter (VIT_13s0019g04660) were also identified. Interestingly the expression of genes encoding an $\mathrm{ABC}$ transporter (VIT_02s0025g00990) and an oligopeptide transporter (OPT, VIT_19s0015g00860) was also differentially expressed between treatments. The expressing of all these genes was up-regulated by $\mathrm{N}$ except for the OPT gene which was down-regulated. It was 2-fold lower in the soil N100 treatment compared to the control. In addition to VviNiR, VviGST3, VviGST4 and $V v i G G T$ which the expression validate the RNA-seq results, the expression of VIT_19s0015g00860 (VviOPT) was confirmed by real-time PCR. It was significantly down regulated by $\mathrm{N}$ at $(\mathrm{v}+35)$ in 2013 and at $(\mathrm{v}+28)$ in 2014 (Additional file 4).

In 2014, only a putative zinc transporter (VIT_19s0085g00740) was common between the two developmental stages.

\section{Discussion}

The aim of this study was to investigate the effect of vine $\mathrm{N}$ status on the content of two major volatile thiols, $4 \mathrm{MSP}$ and $3 \mathrm{SH}$, and the accumulation of the precursors of $3 \mathrm{SH}$ in grape berries and must. The implication of VviGST3, VviGST4 and VviGGT genes in the biosynthetic pathway of $3 \mathrm{SH}$ precursors was also assessed and new candidate genes which might be involved in its genesis were identified.

A complete agronomic approach was set up. Vines were the subject to various levels of $\mathrm{N}$ status, while vine water status and vigor were controlled. This experimental set-up allowed us to study the direct effect of $\mathrm{N}$ nutrition on the targeted metabolites, without an interference with other parameters. The agronomic 


\section{a}

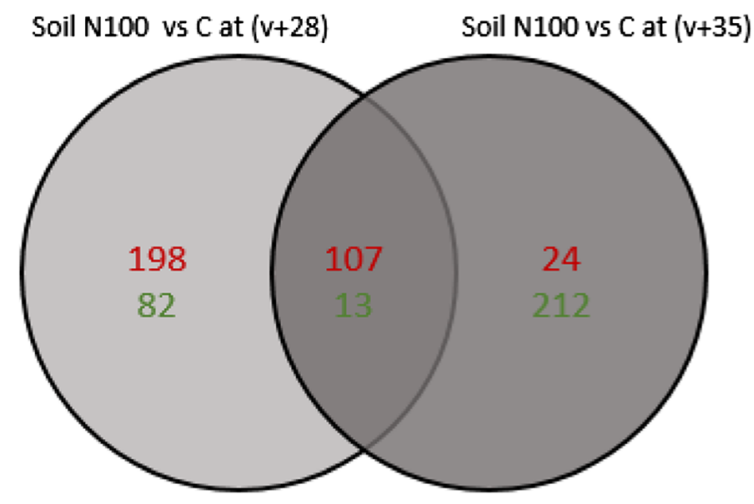

2013 b

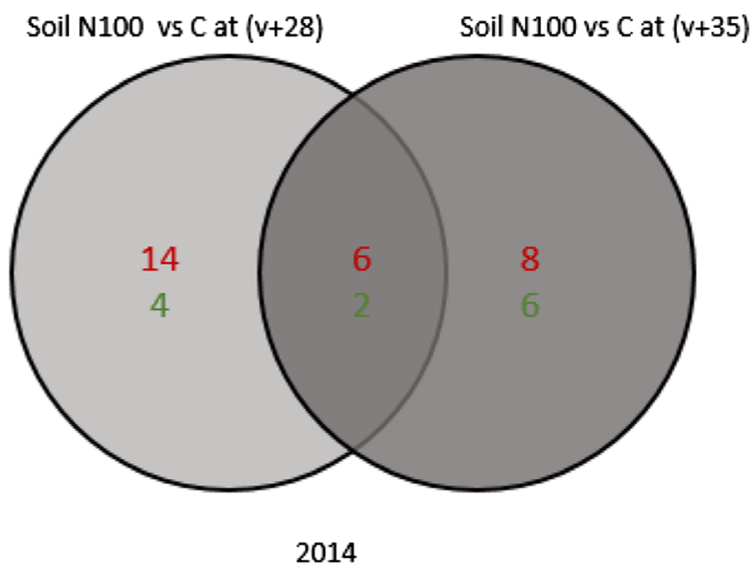

Fig. 9 Comparison of differential gene expression between the soil N100 and the control at two developmental stages in (a) 2013 and (b) 2014. Venn diagrams indicate overlap of all differentially expressed genes obtained from each comparison between the soil N100 treatment and the control at mid-ripening $(v+28)$ and ripeness $(v+35)$. The numbers of up-regulated genes and down-regulated genes are given in red and in green, respectively. C, control

approach was complemented with an analytical approach where $3 \mathrm{SH}$ and its precursors were quantified and with a global transcriptomic approach. This multiapproach study allowed a better understanding of the phenomena and mechanisms underlying the regulation of volatile thiol and volatile thiol production by vine $\mathrm{N}$ status.

In the wine, $3 \mathrm{SH}$ increased with vine $\mathrm{N}$ status. Differences were statistically significant in the majority of combinations. In berries, Glut-3SH content was very low in early stages of development and increased during ripening regardless of vine $\mathrm{N}$ status, in accordance with Roland et al. and Cerreti et al. [51, 52]. The increase was in general greater in $\mathrm{N}+$ conditions compared to the control particularly at mid-ripening and ripeness stages. Cys-3SH was detectable only in Bordeaux and Sancerre berries in 2013. Its concentration was stable during berry ripening and its synthesis was not impacted by vine $\mathrm{N}$ status. Like in the berry, Glut-3SH content in must was affected by vine $\mathrm{N}$ status while Cys-3SH did not reveal any response to $\mathrm{N}$ supply. Both precursors are supposed to be implicated in the genesis of $3 \mathrm{SH}$ and until recently, the Cys-3SH was considered as the major precursor used by the yeast to release the $3 \mathrm{SH}$. In the present study, $\mathrm{N}$ addition did not affect Cys-3SH level while it impacted the content of Glut-3SH and consequently the content of $3 \mathrm{SH}$. This observation seems to indicate that $3 \mathrm{SH}$ could be synthetized from Glut-3SH, independently from Cys-3SH. This result is consistent with Cordente et al. [53], who showed that Glut-3SH can be a direct precursor of $3 \mathrm{SH}$. Still, further studies are required to elucidate the exact pathways for the release of this thiol (i.e. from C6 compounds...) [54-56].
Precursor synthesis was higher in the must compared to berries. As berries were immediately frozen at sampling, precursors synthesis and enzyme activity in the berry were blocked. In must, enzyme activity was maintained, and they were in direct contact with the substrate. This could explain the higher concentrations of precursors in the must, in addition to a putative effect of other pre-fermentation operations. Moreover gene expressions were stimulated by high vine $\mathrm{N}$-status, enhancing precursors synthesis. More investigations are required to obtain a precise explanation of the striking differences in concentration of precursors between berries and must.

The response of vine to $\mathrm{N}$ status in terms of metabolite synthesis or accumulation in the berries and genes profiling was relatively different between 2013 and 2014. This maybe due to the different plant material used in both years (clone 316 grafted on Fercal in 2013 and clone 108 grafted on 161-49 C in 2014) or to differences in climatic conditions, 2014 being warmer year and 2013 a year with more sunshine hours during July and August (data not shown). $\mathrm{N}$ absorption and/or assimilation can be influenced by the clone [57] or by the rootstock [38]. In Bordeaux in 2014, the maximal accumulation of Glut$3 \mathrm{SH}$ in the berries was reached at $(v+28)$ while in 2013 , it was attained at $(v+35)$ with concentrations 2-fold higher for the soil N100 treatment. Moreover, in 2013, more genes were differentially expressed between the two treatments compared to 2014 at both developmental stages indicating that the response of grapevine to environnemental conditions also depend on the genotype of the plant.

In 2011, Kobayashi et al. [27] demonstrated that VviGST3, VviGST4 and VviGGT are key genes in the 
Table 5 Transporter genes differentially expressed between the control and the soil N100 treatment at mid-ripening ( $\mathrm{V}+28)$ or ripeness $(v+35)$ in (a) 2013 and (b) 2014

\begin{tabular}{|c|c|c|c|}
\hline \multicolumn{4}{|l|}{ A } \\
\hline \multirow[t]{2}{*}{ V1_ID } & \multirow[t]{2}{*}{ Best identity description } & \multicolumn{2}{|l|}{ LFC } \\
\hline & & $(v+28)$ & $(v+35)$ \\
\hline \multicolumn{4}{|c|}{ Putative transporters (Bincode 34) } \\
\hline VIT_00s0181g00010 & Sugar transporter 1-like & ns & 0.61 \\
\hline VIT_00s0259g00140 & Oligopeptide transporter (AtOPT3) & ns & 0.83 \\
\hline VIT_01s0011g00600 & Triose-phosphate transmembrane transporter & 0.73 & ns \\
\hline VIT_01s0011g01280 & Cation transmembrane transporter & 0.68 & ns \\
\hline VIT_01s0011g03400 & Proton-dependent oligopeptide transporter (POT) & ns & -0.63 \\
\hline VIT_01s0011g06000 & Vacuolar iron transporter 1 & ns & -0.73 \\
\hline VIT_01s0026g00270 & Potassium transmembrane transporter & 0.67 & ns \\
\hline VIT_01s0026g01570 & Nitrate transporter 1:2-like (AtNRT1:2) & 0.71 & 0.92 \\
\hline VIT_02s0025g00810 & Sodium hydrogen antiporter & -0.71 & ns \\
\hline VIT_02s0025g00990 & ABC transporter family & 0.82 & 1.12 \\
\hline VIT_03s0017g01290 & Fatty acid transporter & -0.66 & ns \\
\hline VIT_03s0017g02170 & Zinc transmembrane transporter & 0.60 & 0.74 \\
\hline VIT_03s0038g02140 & Putative amino acid permease & ns & -0.80 \\
\hline VIT_03s0038g03950 & Mitochondrial substrate carrier family & -0.84 & ns \\
\hline VIT_03s0063g02250 & Polyol transporter 5-like (AtPLT5) & ns & -0.83 \\
\hline VIT_05s0020g03140 & Carbohydrate transmembrane transporter & 0.64 & ns \\
\hline VIT_05s0049g02240 & AWPM-19-like & ns & -0.70 \\
\hline VIT_05s0049g02310 & Integral membrane transporter family & -0.91 & ns \\
\hline VIT_06s0009g01140 & Amino acid transporter family & -0.60 & ns \\
\hline VIT_06s0061g00440 & Heavy-metal-associated domain-containing protein & 0.68 & ns \\
\hline VIT_06s0061g00730 & Gamma tonoplast intrinsic protein (Gamma-TIP) & 1.32 & 1.01 \\
\hline VIT_07s0151g00340 & Sulfate transporter $3 ; 1$ & ns & 1.07 \\
\hline VIT_08s0007g02240 & Cation exchanger 3 & 0.73 & ns \\
\hline VIT_08s0007g04780 & Gamma tonoplast intrinsic protein (Gamma-TIP) & 0.77 & 0.71 \\
\hline VIT_08s0007g06760 & Putative metal tolerance protein (MTPC3) & 0.66 & ns \\
\hline VIT_10s0003g02540 & P-Glycoprotein 9 & ns & -0.77 \\
\hline VIT_10s0003g02620 & AWPM-19-like membrane family & -0.66 & ns \\
\hline VIT_10s0003g05480 & Phosphoglyceride transfer family protein & 1.00 & 1.49 \\
\hline VIT_11s0016g04160 & Sulfate transporter 3;5 (SULTR3;5) & 0.71 & 0.70 \\
\hline VIT_13s0019g04220 & Tryptophan/tyrosine permease family & -0.63 & ns \\
\hline VIT_13s0019g04660 & Amino acid transporter family & 1.22 & 1.31 \\
\hline VIT_13s0067g02220 & Amino acid transporter family & 0.67 & ns \\
\hline VIT_1450030g00340 & Sugar transporter family & ns & 0.60 \\
\hline VIT_14s0068g02190 & Chloride channel protein & 1.23 & 0.89 \\
\hline VIT_14s0108g00430 & Auxin efflux transporter & ns & 0.65 \\
\hline VIT_14s0108g00630 & Amino acid transporter family & 1.29 & ns \\
\hline VIT_15s0046g02420 & Plasma membrane intrinsic protein (PIP1A) & 0.68 & ns \\
\hline VIT_16s0050g01620 & $A B C$ transporter family protein & 0.73 & ns \\
\hline VIT_1850001g02120 & Inorganic anion transmembrane transporter & ns & -0.73 \\
\hline VIT_18s0001g04910 & Sulfate transmembrane transporter (SULTR1;3) & 0.64 & ns \\
\hline
\end{tabular}


Table 5 Transporter genes differentially expressed between the control and the soil N100 treatment at mid-ripening ( $v+28)$ or ripeness $(v+35)$ in (a) 2013 and (b) 2014 (Continued)

\begin{tabular}{|c|c|c|c|}
\hline VIT_18s0041g00590 & Proton-dependent oligopeptide transporter (POT) & ns & 0.87 \\
\hline VIT_19s0015g00860 & Oligopeptide transporter-like (AtOPT1) & -1.12 & -0.96 \\
\hline VIT_19s0090g01480 & Sodium transporter & ns & -0.62 \\
\hline \multicolumn{4}{|l|}{ B } \\
\hline \multirow[t]{2}{*}{ V1_ID } & Best identity description & LFC & \\
\hline & & $(v+28)$ & $(v+35)$ \\
\hline \multicolumn{4}{|c|}{ Putative transporters (Bincode 34) } \\
\hline VIT_01s0010g02440 & Chlorophyll/glutathione-S-conjugate transporter ATPase (AtMRP3-like) & 1.08 & ns \\
\hline VIT_14s0068g02190 & Chloride channel protein & 0.90 & ns \\
\hline VIT_18s0001g02140 & Manganese ion transmembrane transporter & -0.94 & ns \\
\hline VIT_19s0085g00740 & Zinc transmembrane transporter & 0.91 & 1.24 \\
\hline
\end{tabular}

$p$ value $\leq 0.05$ and $\mid$ LFC $\mid \geq 0.6$. C control, $n s$ not significant

biosynthetic pathway of $3 \mathrm{SH}$ precursors and that their expression is correlated to Glut-3SH and Cys-3SH levels in grape berries. Higher transcript abundance of $V v i N i R$ in the berries were observed in soil N100 treatment, confirming that the vines responded to $\mathrm{N}$ supply at a transcriptomic level in our study. Unlike VviGST3, VviGST4 and VviGGT whose transcript abundances were similar in vines with highly different $\mathrm{N}$ status, Glut-3SH content was influenced by N supply. Thus, in the present study, VviGST3 or VviGST4 transcript abundance do not relate to Glut-3SH contents. Hence, it can be assumed that these two genes are not responsible of the variation observed in Glut-3SH levels in berries. The mode of genesis of the different precursors and the potential implication of a VviGST or a VviGGT needs further investigation.

In plants, the glutathione- $S$-transferases are a superfamily of proteins involved in enzymatic detoxification of endo- and xenobiotics. Plant GSTs are divided into six sub-classes namely tau $(\mathrm{U})$, phi $(\mathrm{F})$, zeta $(\mathrm{Z})$, theta (T), lambda (L) and dehydroascorbate reductases [58]. In A. thaliana, AtGSTU25 (GenBank: 838289) was demonstrated to bind to $S$-hexanol-glutathione which can be the product of the addition of glutathione to trans-2-hexenal [59-61]. These compounds serve as precursors of the $3 \mathrm{SH}$ in the grape berries. Among the identified GSTs in 2013, VIT_19s0015g02680 possesses a predicted protein sequence which presents $69 \%$ of similarity with that of AtGSTU25. Taken all together, VIT_19s0015g02680 could be a potential candidate gene encoding an enzyme implicated in the biosynthetic pathway of $3 \mathrm{SH}$ precursors.

In the present study, VviGGT transcript abundance was not affected by vine $\mathrm{N}$ status, and likewise, the level of $\mathrm{Cys}-3 \mathrm{SH}$, the metabolite supposed to be formed in response to its enzymatic activity. The expression of VviGGT gene was not regulated by $\mathrm{N}$, which may explain the absence of an effect of $\mathrm{N}$ on the cysteinylated precursor.

The global transcriptomic approach allowed the identification of genes encoding transporters involved in peptides and oligopeptides transport. In A thaliana, based on sequence similarity and mechanism, three gene families have been shown to transport peptides: (i) the ATP-binding cassette $(\mathrm{ABC})$ superfamily, (ii) the peptide transporter (PTR) or the proton-dependent oligopeptide transporter (POT) family and (iii) the oligopeptide transporter (OPT) family [62].

In this work, an OPT gene (VIT_19s0015g00860, VviOPT1) was identified. In Vitis vinifera, 18 OPT genes were identified that possess a conserved OPT domain essential for their transporter activity [63]. The OPT proteins may be involved in 4 different processes: longdistance metal distribution [64], heavy metal sequestration $[65,66]$, nitrogen mobilization $[62,66]$ and glutathione transport [65-68]. The protein sequence of VviOPT1 possesses $47.9 \%$ of similarity with that of ScOPT1 in S. cerevisiae (GenBank: 853218). Subileau et al. (2009) showed that the knockout mutant of the OPT1 gene in S. cerevisiae reduced the accumulation of $3 \mathrm{SH}$ precursors in grape must. They deduced that the majority of Glut-3SH is transported into yeast via OPT1. In the absence of this transporter, the precursor uptake limited significantly the production of 3SH [55]. Recently, Santiago and Gardner [69] demonstrated that ScOPT1 is required to the conversion of Glut-3SH to $3 \mathrm{SH}$. Noteworthy is the fact that VviOPT1 expression profile was also affected by $\mathrm{N}$ at $(\mathrm{v}+$ 35) stage in 2014 (LFC - 0.71 and $p$ value 0.005 ), however the adjusted $p$ value was above threshold.

Concerning the ABC transporter genes, VIT_02s0025g00990 and VIT_16s0050g01620 responded to $\mathrm{N}$ supply at both stages in 2013. In 2014, another ABC transporter (VIT_01s0010g02440) responded to this nutrient but its expression was only significantly modified at $(v+28)$. In $A$. 
thaliana, $\mathrm{ABC}$ transporters could be involved in glutathione-S-conjugates and chlorophyll catabolism [70].

Among the POT family, VIT_01s0011g03400 which is responsive to $\mathrm{N}$ status, encodes a nitrite transporter similar to a putative transporter involved in nitrite metabolism (73\% of similarity) described in A. thaliana (AT1G68570; GenBank: 843186).

Based on these evidences, the $V v i O P T$ genes and the $A B C$ transporter genes identified in the present study may be potential candidate genes implicated in the transport of GSH or the GSH-S-conjugates that are necessary for the genesis of $3 \mathrm{SH}$ precursors.

In Bordeaux, a significant positive effect of $\mathrm{N}$ supply on Glut-3SH level was observed in 2013 and 2014 while in Sancerre the impact was non-significant. In the Sancerre vineyard in both vintages, vine vigor was increased in soil N100 treatment. The non-significant response of Glut3SH level to N nutrition in Sancerre may be due to a decrease in 3SH precursors synthesis in soil N100 treatment, related to increased vine vigor. Greater leaf areas might have modified the microclimatic conditions in the bunch zone, decreasing the temperature and radiation at the grape level, although no precise micro climatic measurements were carried out. The observed effect could be due either to indirect UV-B or temperature differences. Indeed, an effect of harvest temperature on the concentration of $3 \mathrm{SH}$ precursors was described by Kobayashi et al. [27], suggesting that the accumulation of these molecules depend on the climatic conditions. Light or radiation may stimulate the synthesis of thiol precursor or enhance their degradation. No studies have been published on the direct effect of temperature and radiation on $3 \mathrm{SH}$ precursors, and more research is required on this highly relevant subject. So the lack of impact of $\mathrm{N}$ on Glut-3SH in the Sancerre experiment might be the result of a modification of the microclimate at the level of bunch zone.

The positive effect of nitrogen on $3 \mathrm{SH}$ content in wine could also result from a stabilisation of this compound in berries from high $\mathrm{N}$ vines. Thiols are very sensitive molecules and can be lost due to oxidation reactions in the grape must [71-73]. The presence of antioxidant molecules in wines from soil N100 modality might explain their stabilization. Among these antioxidants, glutathione (GSH) plays an important role in the stability of volatile thiols in wine. This molecule is very important in oenology, especially for the production of white wine. GSH content responds positively to $\mathrm{N}$ status $[28,29]$ and its implication in the biosynthetic pathway of $3 \mathrm{SH}$ was recently demonstrated [22]. The role of glutathione on the synthesis or stability of volatile thiol, in particular with regard to $3 \mathrm{SH}$, requires further research. It needs to be clarified if higher 3SH levels in wine in the presence of high GSH levels results from increased production or greater stability of $3 \mathrm{SH}$.

\section{Conclusion}

The effect of vine $\mathrm{N}$ status on volatile thiols in wines from Vitis vinifera cv Sauvignon blanc wines and their precursors in grapes and must was investigated combining agronomic, analytic and transcriptomic approaches. An effect of vine $\mathrm{N}$ status on $3 \mathrm{SH}$ was found, while $\mathrm{N}$ did not have an effect on 4MSP. High vine N status increased 3SH level in wine through an increase of Glut-3SH content in grape berries and must, but did not impact Cys-3SH level. This observation seems to indicate that $3 \mathrm{SH}$ could be synthetized from Glut-3SH, independently from Cys-3SH and from the activity of VviGST3, VviGST4 and VviGGT. In the berry, the impact of $\mathrm{N}$ on Glut-3SH involves putatively another type of GSTs, as well as oligopeptide transporters.

\section{Sample collection in a commercial vineyard}

Samples were collected for this study at the commercial vineyard of ChâteauCouhins (Pessac-Léognan, France) and Domaine Fontaine-Audon (18240 SainteGemme en Sancerrois, France) with the authorization of the owners and following the INRA's ethics charter (http://institut.inra.fr/en/Objectives/Promoting-ethicsand-a-code-of-conduct/All-reports/Ethics-Charter/Professional-Ethics-Charter).

\section{Additional files}

Additional file 1: Genes differentially expressed in response to $\mathrm{N}$ at $(v+28)$ and $(v+35)$ in 2013. $p$ value $\leq 0.05$ and $\mid$ LFC | $\geq 0.6$. C, control; ns, not significant. (XLSX $49 \mathrm{~kb}$ )

Additional file 2: Genes differentially expressed in response to $\mathrm{N}$ at $(v+28)$ and $(v+35)$ in 2014. $p$ value $\leq 0.05$ and $\mid$ LFC $\mid \geq 0.6$. C, control; $\mathrm{ns}$, not significant. (XLSX $12 \mathrm{~kb}$ )

Additional file 3: Genes differentially expressed in response to $N$ at $(v+28)$ and $(v+35)$ in 2013 and 2014. $p$ value $\leq 0.05$ and $|L F C| \geq 0.6$. C, control; ns, not significant. (XLSX $10 \mathrm{~kb}$ )

Additional file 4: Changes in relative transcript levels of VIT_19s0015g00860 $(V V i O P T)$ in grape berries at mid-ripeness $(v+28)$ and ripeness $(v+35)$ in the Bordeaux experimental site. Transcript levels were analyzed by real-time PCR and are shown relative to expression of V viGAPDH and VviActin in each sample. All data are presented as mean of three biological replicates and two technical replicates. Letters indicate significant differences. Error bars indicate Standard Error (SE). Statistical significance was determined by Student's $t$ test ( $p$ value $\leq$ 0.05). (DOCX $30 \mathrm{~kb})$

\footnotetext{
Abbreviations

3SH, 3-sulfanylhexan-1-ol; 4MSP, 4-methyl-4-sulfanylpentan-2-one; 6SH, 6-sulfanylhexanol; ABC, ATP-binding cassette; Cys-3SH, S-3-(hexan-1-ol)-cysteine; Cys-4MSP, S-4-(4-methylpentan-2-one)-L-cysteine; Cysgly-3SH, S-3-(hexan-1-ol)cysteinylglycine; GGT, Y-glutamyltranspeptidase; Glut-3SH, S-3-(hexan-1-ol)glutathione; Glut-4MSP, S-4-(4-methylpentan-2-one)-L-glutathione; GO, gene ontology; GSH, glutathione; GST, glutathione-S-transferase; LFC, $\log _{2}$ (FoldChange); LOQ, limit of quantification; MMSB, 4-methoxy-2-methyl-2sulfanylbutan; N, nitrogen; NiR, nitrite reductase; OPT, oligopeptide transporter; POT, proton-dependent oligopeptide transporter; PTR, peptide transporter; RPKM, reads per exon kilo base per million mapped sequence reads; Soil N100, $100 \mathrm{~kg}$ per hectare of nitrogen applied to the soil; $v$, mid-veraison; $v+28$, mid-ripening; $v+35$, ripeness; $v-20$, bunch closure; YAN, yeast available nitrogen
} 


\section{Acknowledgements}

Kleopatra Nikolaou, Paul Andres, Manon Barron, Claude Bonnet, Christel Renaud, Warren Albertin, Bernard Douens, Nicolas Hocquard, Jean-Pierre Petit, Jean-Pascal Tandonnet, Jean-Pierre Robert, Eloïse Brouard, and Stelina Brillant are greatly thanked for their technical help.

The members of SICAVAC team (Service Interprofessionnel de Conseil Agronomique, de Vinification et d'Analyses du Centre), Château Couhins and Domaine Fontaine-Audon are deeply appreciated for their collaboration. Sequencing was performed by the IGBMC Microarray and Sequencing platform, member of the FG National Infrastructure, funded by the Agence Nationale pour la Recherche (ANR-10-INBS-0009).

\section{Funding}

The project was supported by the interprofessional council of Bordeaux wine (CIVB), FranceAgriMer and Bordeaux Sciences Agro.

\section{Availability of data and materials}

A supporting data can be found within the manuscript and its additional file. The RNA-seq dataset was deposited in the Gene Expression Omnibus (GEO), National Center for Biotechnology Information (NCBI) under the accession number GSE77895.

\section{Authors' contribution}

$\mathrm{PH}$ conducted the experiment and measurements on Bordeaux vineyards, processed samples for precursor analyses, measured 3SH and 4MSP contents by GC-MS, and 3SH precursors levels by LC-MS, assessed primary metabolites, extracted RNA, studied genes expression by quantitative PCR, analyzed the RNA-seq dataset and wrote the body of the manuscript. SG participated in genes expression analysis and provided technical support in the transcriptomic approach. CT participated in volatile thiols ants their precursors analysis and provided technical support in GC-MS and LC-MS machines sample run. CK analyzed the reads and performed the statistical analysis of the RNA-seq dataset. AH participated in the running of the experiment in Bordeaux vineyards. GH contributed to biochemical analysis. EG participated in data interpretation, and performed manuscript critical reading. SD corrected and edited the manuscript. CVL conceived and coordinated the project and the experimental design. PH, SG, $C T, C K, A H, G H, E G, P D, S D$ and CVL participated to the experimental design of this study, and in the interpretation of data. These authors reviewed, corrected, and edited the manuscript. All authors approved the final version of the manuscript.

\section{Competing interests}

The authors declare that they have no competing interests.

\section{Consent to publish}

Not applicable.

\section{Ethics approval and consent to participate}

Our ethics charter is available on: http://institut.inra.fr/en/Objectives/ Promoting-ethics-and-a-code-of-conduct/All-reports/Ethics-Charter/ Professional-Ethics-Charter.

\section{Author details}

'Univ. de Bordeaux, Institut des Sciences de la Vigne et du Vin (ISW), Ecophysiologie et Génomique Fonctionnelle de la Vigne (EGFV), UMR 1287, 33140 Villenave d'Ornon, France. ${ }^{2}$ Bordeaux Sciences Agro, Institut des Sciences de la Vigne et du Vin (ISW), Ecophysiologie et Génomique Fonctionnelle de la Vigne (EGFV), UMR 1287, 33140 Villenave d'Ornon, France. ${ }^{3}$ INRA, Institut des Sciences de la Vigne et du Vin (ISW), Ecophysiologie et Génomique Fonctionnelle de la Vigne (EGFV), UMR 1287, 33140 Villenave d'Ornon, France. ${ }^{4}$ Univ. de Bordeaux, Institut des Sciences de la Vigne et du Vin (ISW), Unité de recherche Enologie, EA 4577, 33140 Villenave d'Ornon, France. ${ }^{5}$ INRA, Institut des Sciences de la Vigne et du Vin (ISW), USC 1366 Enologie, 33140 Villenave d'Ornon, France. ${ }^{6}$ Univ. de Strasbourg, Institut de Génétique et de Biologie Moléculaire et Cellulaire (IBGMC), Institut National de la Santé et de la Recherche Médicale U 964, Centre National de Recherche Scientifique UMR 7104, 67404 IIlkirch, France.

Received: 4 March 2016 Accepted: 20 June 2016

Published online: 08 August 2016

\section{References}

1. Ferreira V. Volatile aroma compounds and wine sensory attributes. In: Managing wine quality. 2010. p. 3-28.

2. Coetzee C, Brand J, Emerton G, Jacobson D, Silva Ferreira AC, du Toit WJ. Sensory interaction between 3-mercaptohexan-1-ol, 3-isobutyl-2-methoxypyrazine and oxidation-related compounds. Aust J Grape Wine Res. 2015;21:179-88.

3. Ribéreau-Gayon P, Glories Y, Maujean A, Dubourdieu D. Varietal aroma. In: Handbook of enology: the chemistry of wine stabilization and treatments, vol. 2. 2nd ed. 2006. p. 205-30.

4. Peyrot des Gachons C, van Leeuwen C, Tominaga T, Soyer JP, Gaudillère JP, Dubourdieu D. Influence of water and nitrogen deficit on fruit ripening and aroma potential of Vitis vinifera L. Cv. Sauvignon blanc in field conditions. J Sci Food Agric. 2005;85:73-85.

5. Bayonove C, Cordonnier R, Dubois P. Study of an aromatic characteristic fraction of cabernet-sauvignon grape variety, identification of 2-methoxy-3isobutyl-pyrazine. Comptes rendus Hebd des séances l'académie des Sci série D. 1975;281:75-8.

6. Helwi P, Habran A, Guillaumie S, Thibon C, Hilbert G, Gomes E, Delrot S, Darriet $P$, van Leeuwen $C$. Vine nitrogen status does not have a direct impact on 2 methoxy-3-isobutylpyrazine in grape berries and wines. J Agric Food Chem. 2015:63:9789-802.

7. Park SK, Morrison JC, Adams DO, Noble AC. Distribution of free and glycosidically bound monoterpenes in the skin and mesocarp of Muscat of Alexandria grapes during development. J Agric Food Chem. 1991;39:514-8.

8. Siebert TE, Wood C, Elsey GM, Pollnitz AP. Determination of rotundone, the pepper aroma impact compound, in grapes and wine. J Agric Food Chem. 2008:56:3745-8.

9. Ebeler SE, Thorngate $\mathrm{JH}$. Wine chemistry and flavor: looking into the crystal glass. J Agric Food Chem. 2009;57:8098-108.

10. González-Barreiro C, Rial-Otero R, Cancho-Grande B, Simal-Gándara J. Wine aroma compounds in grapes: a critical review. Crit Rev Food Sci Nutr. 2015:55:202-18

11. Swiegers $J H$, Pretorius IS. Modulation of volatile sulfur compounds by wine yeast. Appl Microbiol Biotechnol. 2007;74:954-60.

12. Darriet $P$, Tominaga $T$, Lavigne $V$, Boidron JN, Dubourdieu D. Identification of a powerful aromatic component of Vitis vinifera L. var. Sauvignon wines: 4-mercapto-4-methylpentan-2-one. Flavour Fragr J. 1995;10:385-92.

13. Tominaga $T$, Furrer A, Henry $R$, Dubourdieu D. Identification of new volatile thiols in the aroma of Vitis vinifera L. var. Sauvignon blanc wines. Flavour Fragr J. 1998;13:159-62.

14. Tominaga T, Darriet P, Dubourdieu D. Identification de l'acétate de 3mercaptohexanol, composé à forte odeur de buis, intervenant dans l'arôme des vins de Sauvignon. Vitis. 1996;35:207-10.

15. Tominaga T, Peyrot des Gachons C, Dubourdieu D. A new type of flavor precursors in Vitis vinifera L. CV. Sauvignon blanc: S-cysteine conjugates. J Agric Food Chem. 1998;46:5215-9.

16. Peyrot Des Gachons C, Tominaga T, Dubourdieu D. Sulfur aroma precursor present in S-glutathione conjugate form: identification of S-3-(hexan-1-ol)glutathione in must from Vitis vinifera L. cv. Sauvignon blanc. J Agric Food Chem. 2002;50:4076-9.

17. Fedrizzi B, Pardon KH, Sefton MA, Elsey GM, Jeffery DW. First identification of 4-S-glutathionyl-4-methylpentan-2-one, a potential precursor of 4mercapto-4-methylpentan-2-one, in Sauvignon blanc juice. J Agric Food Chem. 2009;57:991-5.

18. Thibon C, Shinkaruk S, Jourdes M, Bennetau B, Dubourdieu D, Tominaga T. Aromatic potential of botrytized white wine grapes: identification and quantification of new cysteine-S-conjugate flavor precursors. Anal Chim Acta. 2010;660:190-6.

19. Tominaga T, Masneuf I, Dubourdieu D: Mise en evidence d'un S-conjugue de la cysteine, précurseur d'arôme du Sauvignon [4-methyl-4-mercaptopentan-2one; beta-lyase]. J Int Sci Vigne Vin. 1995;29:227-32.

20. Murat ML, Tominaga T, Dubourdieu D. Assessing the aromatic potential of cabernet-sauvignon and merlot musts used to produce rose wine by assaying the cysteinylated precursor of 3-mercaptohexan-1-ol. J Agric Food Chem. 2001:49:5412-7

21. Kobayashi H, Takase H, Kaneko K, Tanzawa F, Takata R, Suzuki S, Konno T. Analysis of S-3-(hexan-1-ol)-glutathione and S-3-(hexan-1-ol)-I-cysteine in Vitis vinifera L. Cv. Koshu for aromatic wines. Am J Enol Vitic. 2010;2:176-85.

22. Thibon C, Cluzet S, Mérillon JM, Darriet P, Dubourdieu D. 3-Sulfanylhexanol precursor biogenesis in grapevine cells: the stimulating effect of Botrytis cinerea. J Agric Food Chem. 2011;59:1344-51. 
23. Capone DL, Pardon KH, Cordente AG, Jeffery DW. Identification and quantitation of 3-S-cysteinylglycinehexan-1-ol (Cysgly-3-MH) in Sauvignon blanc grape juice by HPLC-MS/MS. J Agric Food Chem. 2011;59:11204-10.

24. Thibon C, Böcker C, Shinkaruk S, Moine V, Darriet P, Dubourdieu D. Identification of S-3-(hexanal)-glutathione and its bisulfite adduct in grape juice from Vitis vinifera L. cv. Sauvignon blanc as new potential precursors of 3SH. Food Chem. 2016;199:711-9.

25. Mueller MJ. Archetype signals in plants: the phytoprostanes. Curr Opin Plant Biol. 2004;7:441-8

26. Kishimoto K, Matsui K, Ozawa R, Takabayashi J. Volatile C6-aldehydes and allo-ocimene activate defense genes and induce resistance against Botrytis cinerea in Arabidopsis thaliana. Plant Cell Physiol. 2005;46:1093-102.

27. Kobayashi H, Takase H, Suzuki Y, Tanzawa F, Takata R, Fujita K, Kohno M, Mochizuki M, Suzuki S, Konno T. Environmental stress enhances biosynthesis of flavor precursors, S-3-(hexan-1-ol)-glutathione and S-3-(hexan-1-ol)-Lcysteine, in grapevine through glutathione S-transferase activation. J Exp Bot. 2011;62:1325-36.

28. Choné $X$, Lavigne-Cruège $V$, Tominaga $T$, van Leeuwen $C$, Castagnède $C$, Saucier C, Dubourdieu D. Effect of vine nitrogen status on grape aromatic potential: flavor precursors (S-cysteine conjugates), glutathione and phenolic content in Vitis vinifera L.cv.Sauvignon blanc grape juice. J Int Sci Vigne Vin. 2006:40:1-6.

29. Lacroux F, Tregoat $O$, van Leeuwen $C$, Pons A, Tominaga T, Lavigne-Cruège V, Dubourdieu D. Effect of foliar nitrogen and sulphur application on aromatic expression of Vitis vinifera L. cv. Sauvignon blanc. J Int des Sci la Vigne du Vin. 2008;42:125-32.

30. Subileau M, Schneider R, Salmon J-M, Degryse E. Nitrogen catabolite repression modulates the production of aromatic thiols characteristic of Sauvignon blanc at the level of precursor transport. FEMS Yeast Res. 2008:8:771-80.

31. Scholander PF, Hammel HT, Hemmingsen EA, Bradstreet ED. Hydrostatic pressure and osmotic potential in leaves of mangroves and some other plants. Proc Natl Acad Sci U S A. 1964;52:119-25.

32. Choné $X$, van Leeuwen C, Gaudillère JP. Stem water potential is a sensitive indicator of grapevine water status. Ann Bot. 2001;87:477-83.

33. Mabrouk H, Carbonneau A. Une méthode simple de détermination de la surface foliaire de la vigne (Vitis vinifera L.). Progrès Agric Vitic. 1996;113:392-8.

34. van Leeuwen C, Friant P, Soyer JP, Molot C, Chone X, Dubourdieu D. L'intéret du dosage de l'azote total et de l'azote assimilable dans le môut comme indicateur de la nutrition azotée de la vigne. J Int Sci Vigne Vin. 2000;34:75-82.

35. Tregoat $O$, van Leeuwen $C$, Choné $X$, Gaudillère J-P. The assessment of vine water and nitrogen uptake by means of physiological indicators influence on vine development and berry potential (Vitis vinifera L. Cv Merlot, 2000, Bordeaux). J Int des Sci la Vigne du Vin. 2002;36:133-42.

36. Destrac A, Flutre T, Renaud C, Morin E, Durand L, Delrot S, van Leeuwen C. The use of fourrier transform infrared spectroscopy in phenotyping berries from the grapevine Vitis vinifera L. In: XIXth International Giesco meeting. Montpellier: Pech Rouge; 2015. p. 641-5.

37. Tominaga T, Murat ML, Dubourdieu D. Development of a method for analyzing the volatile thiols involved in the characteristic aroma of wines made from Vitis vinifera L. Cv. Sauvignon blanc. J Agric Food Chem. 1998;46:1044-8.

38. Helwi P, Thibon C, Habran A, Hilbert G, Guillaumie S, Delrot S, Darriet P, van Leeuwen $C$. Effect of vine nitrogen status, grapevine variety and rootstock on the levels of berry S-glutathionylated and S-cysteinylated precursors of 3-sulfanylhexan-1-ol. J Int Sci Vigne Vin. 2015;49:253-65.

39. Reid KE, Olsson N, Schlosser J, Peng F, Lund ST. An optimized grapevine RNA isolation procedure and statistical determination of reference genes for real-time RT-PCR during berry development. BMC Plant Biol. 2006;6:27.

40. Guillaumie S, Ilg A, Réty S, Brette M, Trossat-Magnin C, Decroocq S, Léon C, Keime C, Ye T, Baltenweck-Guyot R, Claudel P, Bordenave L, Vanbrabant S, Duchêne E, Delrot S, Darriet P, Hugueney P, Gomès E. Genetic analysis of the biosynthesis of 2-methoxy-3-isobutylpyrazine, a major grape-derived aroma compound impacting wine quality. Plant Physiol. 2013;162:604-15.

41. Kim D, Pertea G, Trapnell C, Pimentel H, Kelley R, Salzberg SL. TopHat2: accurate alignment of transcriptomes in the presence of insertions, deletions and gene fusions. Genome Biol. 2013;14:36.

42. Langmead B, Salzberg SL. Fast gapped-read alignment with bowtie 2. Nat Methods. 2012;9:357-9.

43. Anders S, Pyl P, Huber W. HTSeq - a python framework to work with high-throughput sequencing data. Bioinformatics. 2015;31:166-9.

44. Love MI, Huber W, Anders S. Moderated estimation of fold change and dispersion for RNA-Seq data with DESeq2. Genome Biol. 2014;15:550.
45. Benjamini Y, Hochberg Y: Controlling the false discovery rate: a practical and powerful approach to multiple testing. J. R. Stat. Soc. 1995;57:289-300

46. Thimm O, Bläsing O, Gibon Y, Nagel A, Meyer S, Krüger P, Selbig J, Müller LA., Rhee SY, Stitt M. MAPMAN: a user-driven tool to display genomics data sets onto diagrams of metabolic pathways and other biological processes. Plant J. 2004;37:914-39.

47. Grant-Preece PA, Pardon KH, Capone DL, Cordente AG, Sefton MA, Jeffery DW, Elsey GM. Synthesis of wine thiol conjugates and labeled analogues: fermentation of the glutathione conjugate of 3-mercaptohexan-1-ol yields the corresponding cysteine conjugate and free thiol. J Agric Food Chem. 2010;58:1383-9.

48. Capone DL, Sefton MA, Hayasaka Y, Jeffery DW. Analysis of precursors to wine odorant 3-mercaptohexan-1-ol using HPLC-MS/MS: resolution and quantitation of diastereomers of 3-S-cysteinylhexan-1-ol and 3-Sglutathionylhexan-1-ol. J Agric Food Chem. 2010;58:1390-5.

49. Schüttler A. Influencing factors on aromatic typicality of wines from Vitis vinifera L. cv. Riesling-sensory, chemical and viticultural insights, doctoral dissertation, Bordeaux 2. 2012.

50. Masclaux-Daubresse C, Valadier MH, Carrayol E, Reisdorf-Cren M, Hirel B. Diurnal changes in the expression of glutamate dehydrogenase and nitrate reductase are involved in the $\mathrm{C} / \mathrm{N}$ balance of tobacco source leaves. Plant Cell Environ. 2002;25:1451-62.

51. Roland A, Vialaret J, Razungles A, Rigou P, Schneider R. Evolution of Scysteinylated and S-glutathionylated thiol precursors during oxidation of Melon B. and Sauvignon blanc musts. J Agric Food Chem. 2010;58:4406-13.

52. Cerreti M, Esti M, Benucci I, Liburdi K, de Simone C, Ferranti P. Evolution of S-cysteinylated and S-glutathionylated thiol precursors during grape ripening of Vitis vinifera L. cvs Grechetto, Malvasia del Lazio and Sauvignon blanc. Aust J Grape Wine Res. 2015;21:411-6.

53. Cordente AG, Capone DL, Curtin CD. Unravelling glutathione conjugate catabolism in Saccharomyces cerevisiae: the role of glutathione/dipeptide transporters and vacuolar function in the release of volatile sulfur compounds 3-mercaptohexan-1-ol and 4-mercapto-4-methylpentan-2-one. Appl Microbiol Biotechnol. 2015;99:9709-22.

54. Schneider R, Charrier F, Razungles A, Baumes R. Evidence for an alternative biogenetic pathway leading to 3-mercaptohexanol and 4-mercapto-4methylpentan-2-one in wines. Anal Chim Acta. 2006;563:58-64.

55. Subileau M, Schneider R, Salmon J-M, Degryse E. New insights on 3mercaptohexanol (3MH) biogenesis in Sauvignon blanc wines: Cys-3MH and (E)-hexen-2-al are not the major precursors. J Agric Food Chem. 2008;56:9230-5.

56. Harsch MJ, Gardner RC. Yeast genes involved in sulfur and nitrogen metabolism affect the production of volatile thiols from Sauvignon blanc musts. Appl Microbiol Biotechnol. 2013;97:223-35.

57. Tomasi N, Monte R, Varanini Z, Cesco S, Pinton R. Induction of nitrate uptake in sauvignon blanc and chardonnay grapevines depends on the scion and is affected by the rootstock. Aust J Grape Wine Res. 2015;21:331-8.

58. Jiang HW, Liu MJ, Chen IC, Huang CH, Chao LY, Hsieh HL. A glutathione Stransferase regulated by light and hormones participates in the modulation of Arabidopsis seedling development. Plant Physiol. 2010;154:1646-58.

59. Feussner I, Wasternack C. The lipoxygenase pathway. Annu Rev Plant Biol. 2002;53:275-97.

60. Davoine C, Falletti O, Douki T, lacazio G, Ennar N, Montillet JL, Triantaphylidès $C$. Adducts of oxylipin electrophiles to glutathione reflect a 13 specificity of the downstream lipoxygenase pathway in the tobacco hypersensitive response. Plant Physiol. 2006;140:1484-93.

61. Dixon DP, Edwards R. Selective binding of glutathione conjugates of fatty acid derivatives by plant glutathione transferases. J Biol Chem. 2009;284:21249-56.

62. Koh S, Wiles AM, Sharp JS, Naider FR, Becker JM, Stacey G. An oligopeptide transporter gene family in Arabidopsis. Plant Physiol. 2002;128:21-9.

63. Cao J, Huang J, Yang Y, Hu X. Analyses of the oligopeptide transporter gene family in poplar and grape. BMC Genomics. 2011;12:465.

64. Stacey MG, Patel A, McClain WE, Mathieu M, Remley M, Rogers EE, Gassmann W, Blevins DG, Stacey G. The Arabidopsis AtOPT3 protein functions in metal homeostasis and movement of iron to developing seeds. Plant Physiol. 2008;146:589-601.

65. Cagnac O, Bourbouloux A, Chakrabarty D, Zhang MY, Delrot S. AtOPT6 transports glutathione derivatives and is induced by primisulfuron. Plant Physiol. 2004;135:1378-87. 
66. Pike S, Patel A, Stacey G, Gassmann W. Arabidopsis OPT6 is an oligopeptide transporter with exceptionally broad substrate specificity. Plant Cell Physiol. 2009;50:1923-32

67. Bogs J, Bourbouloux A, Cagnac O, Wachter A, Rausch T, Delrot S. Functional characterization and expression analysis of a glutathione transporter, BjGT1, from Brassica juncea: evidence for regulation by heavy metal exposure. Plant Cell Environ. 2003;26:1703-11.

68. Zhang MY, Bourbouloux A, Cagnac O, Srikanth CV, Rentsch D, Bachhawat AK, Delrot S. A novel family of transporters mediating the transport of glutathione derivatives in plants. Plant Physiol. 2004;134:482-91.

69. Santiago M, Gardner RC. Yeast genes required for conversion of grape precursors to varietal thiols in wine. FEMS Yeast Res. 2015;15:fov034.

70. Tommasini R, Vogt E, Fromenteau M, Hörtensteiner S, Matile P, Amrhein N, Martinoia E. An ABC-transporter of Arabidopsis thaliana has both glutathione-conjugate and chlorophyll catabolite transport activity. Plant J. 1998;13:773-80.

71. Anderson ME. Glutathione: an overview of biosynthesis and modulation. Chem Biol Interact. 1998;111-112:1-14.

72. Lavigne $\mathrm{V}$, Pons A, Dubourdieu D. Assay of glutathione in must and wines using capillary electrophoresis and laser-induced fluorescence detection. Changes in concentration in dry white wines during alcoholic fermentation and aging. J Chromatogr A. 2007;1139:130-5.

73. Kritzinger EC, Bauer FF, du Toit WJ. Role of glutathione in winemaking: a review. J Agric Food Chem. 2013;61:269-77.

\section{Submit your next manuscript to BioMed Central} and we will help you at every step:

- We accept pre-submission inquiries

- Our selector tool helps you to find the most relevant journal

- We provide round the clock customer support

- Convenient online submission

- Thorough peer review

- Inclusion in PubMed and all major indexing services

- Maximum visibility for your research

Submit your manuscript at www.biomedcentral.com/submit 